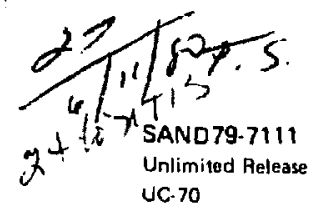

\title{
The Thermomechanical Response of WIPP Repositories
}

\section{MASTER}

D. E. Maxwell, K. K. Wahi, B. Dial

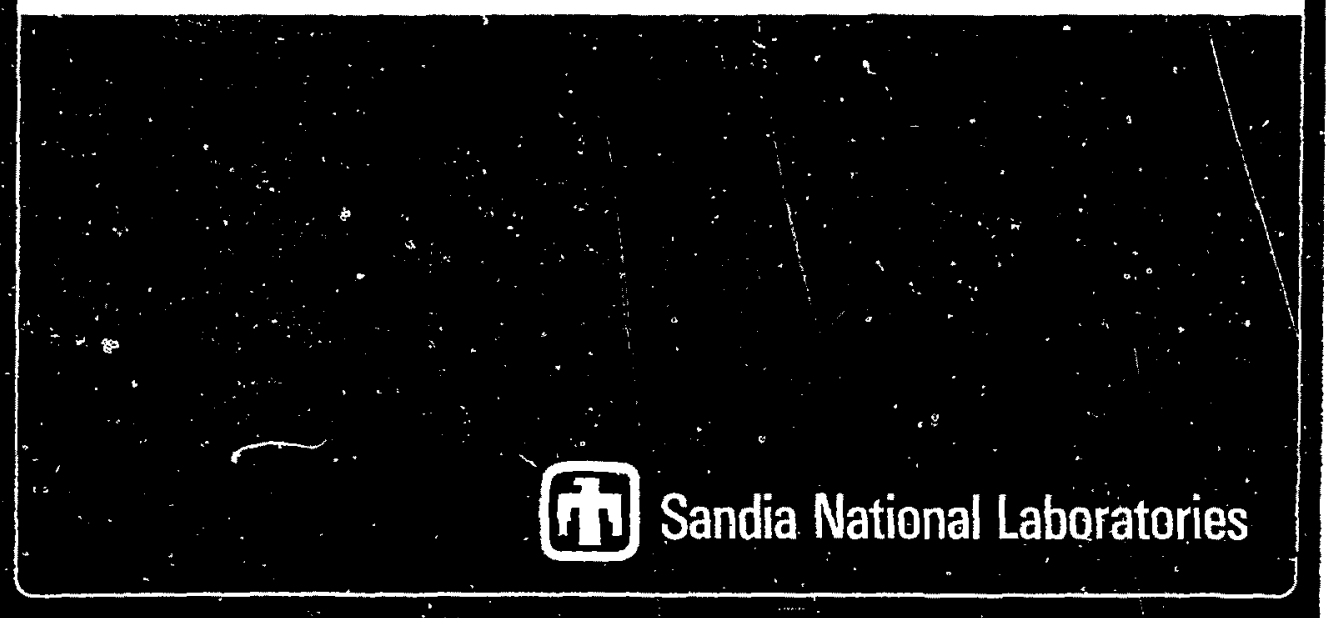




\section{SAND79-7111}

$S A$ I - FR- 445

Unl imitod Relcase

frinted May 1981)

THE THERMOMFCHANICAL RESPONSE OF MIPP RFPOSITORIFS

D. F. Maxivell, K. K. Wahi, anc? B. i ia!

Science Applications, Tnc.

2450 Washington Avenue

San Laandro, CA 94577

and

Civil systems, Incorporatad

2201 San Pedro, NE

Building 3 , suite 21.4

Alburrograun, Now Mryi 8 ? 110

\section{Preparen for:}

Sanria National laboratories

P. O. Box 5800

Albuguerque, New MexicC 87185

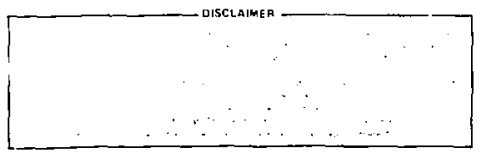

Contract No. $07-3269$

october 26,1978 


\section{FOR FWORD}

Th ralsilations prosented here were pertormed tor Sandia

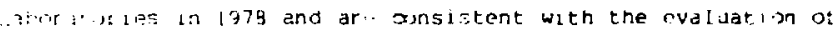

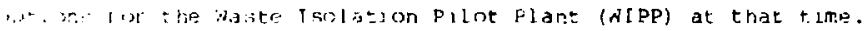

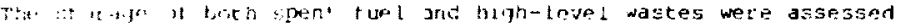

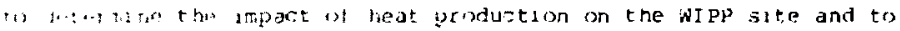

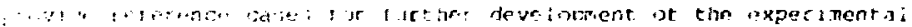
: $1 \cdot:$

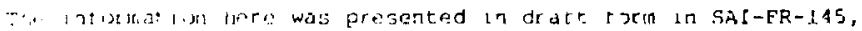
$\because \because \cdots$, , rer A, solirations, . ne. 


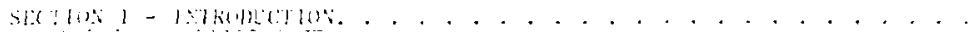

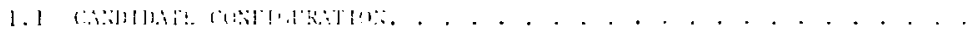

i. d dinlitilsick, . , . . . . . . . . . . . . . . . . . . .

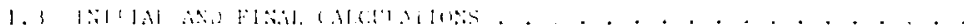

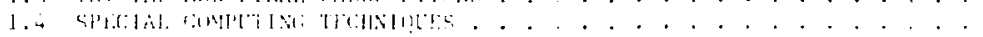

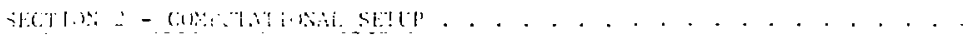

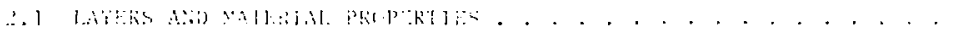

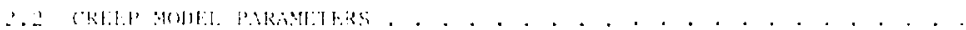

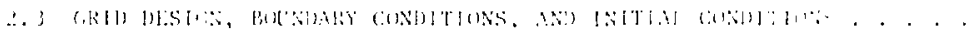

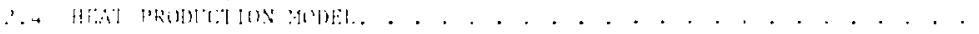

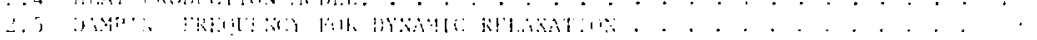

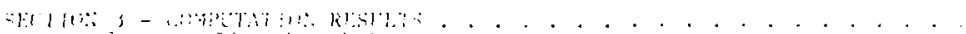

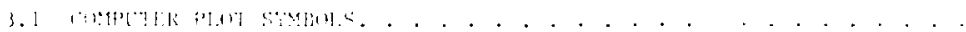

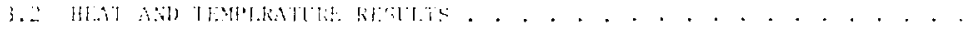

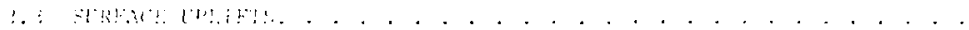

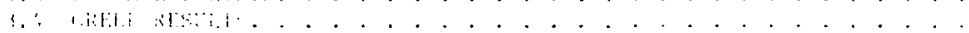

. ,

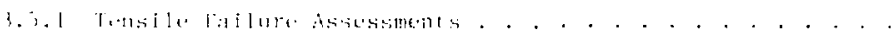

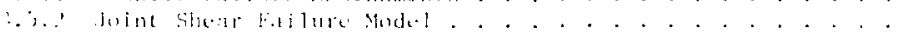

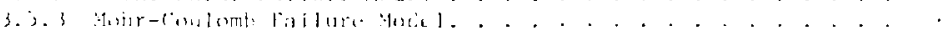

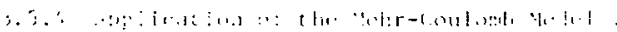

今.

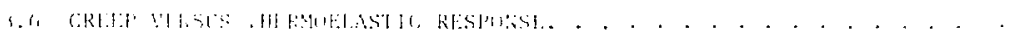

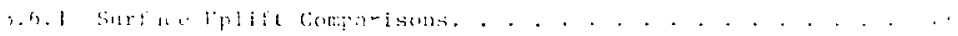

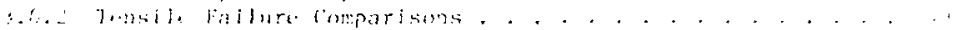

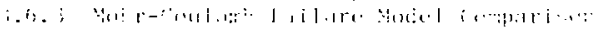

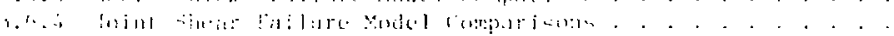

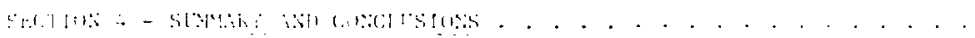

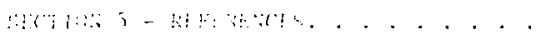




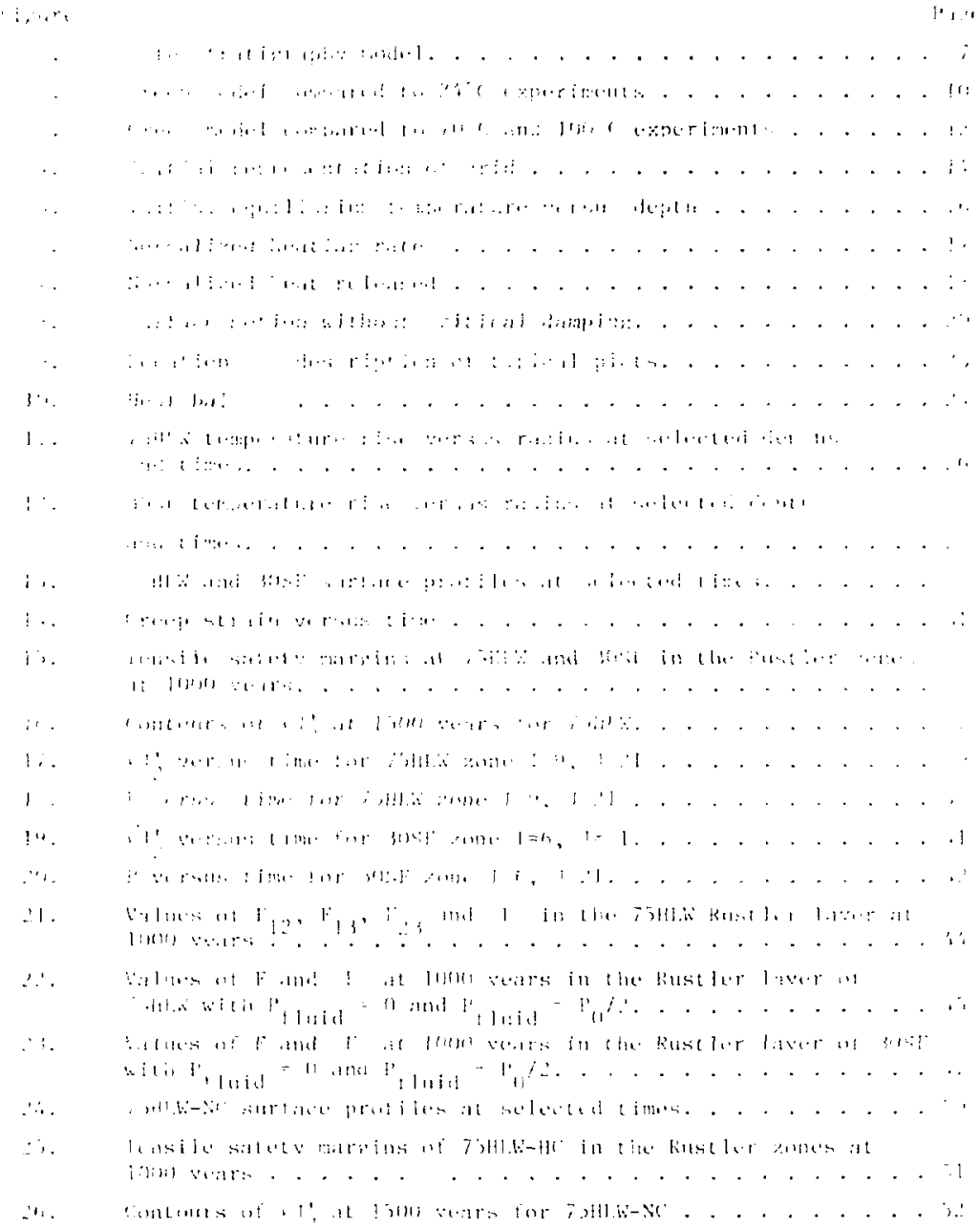




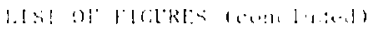

fi i:tur

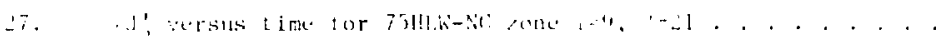

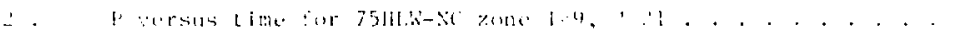

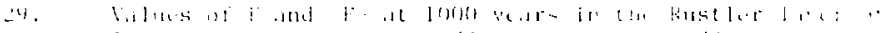

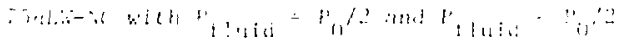

$\because$ 


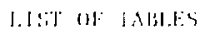

$1 \div !$

inis:

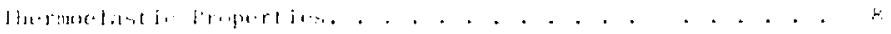

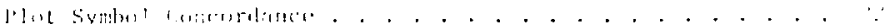


$\operatorname{SinHION} 1$

\section{INTROIJICTIOS ION}

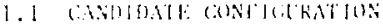

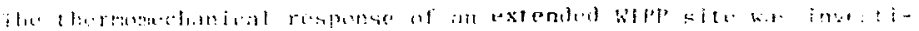

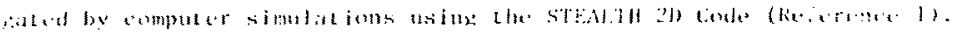

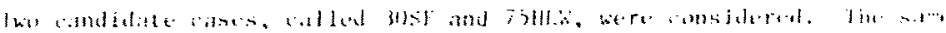

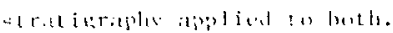

30)

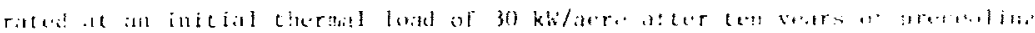

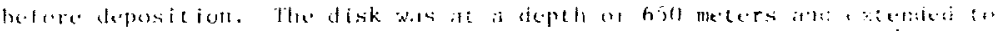

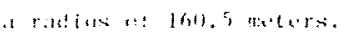

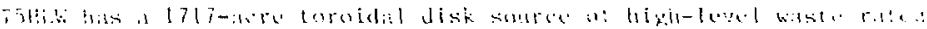

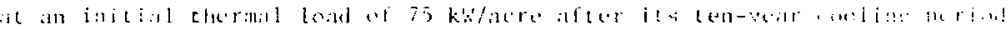

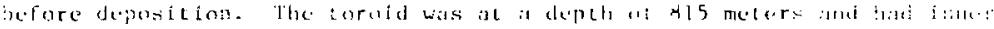

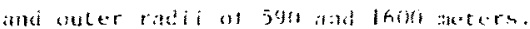

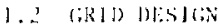

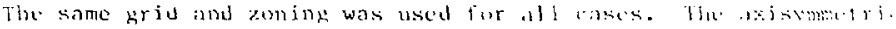

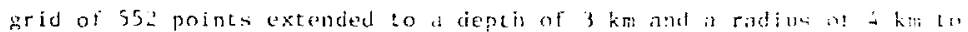

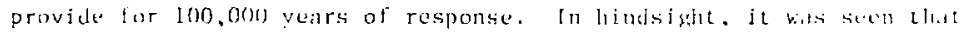

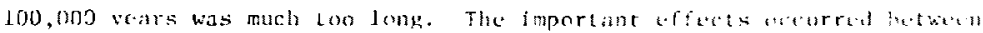

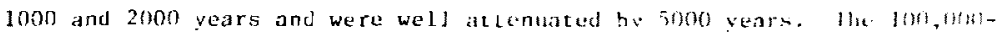
year grid design was not optimized for the important early time at tat and future prids shoutd be designed accorojingle. In partiatlar, it was necessary to accept non-physical oscillations ior about loh veras in

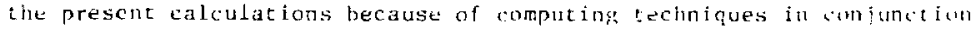
with cust constraints. A betcer design, at constant ast, would have restricted these oscillations to the first lon vatus, wall beinte the levelopment of the important responsts. 


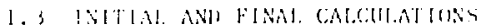

The valeulations were fjrst performed with an erroneous injtial rendition corresponding to a lintior comperature distribution with denth.

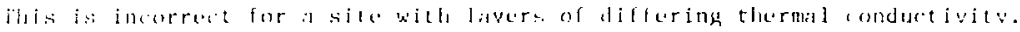
The resilt wis an anomalous surface subsidence at late times as the tem-

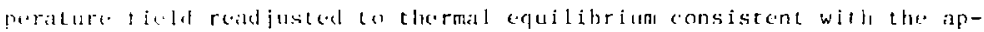

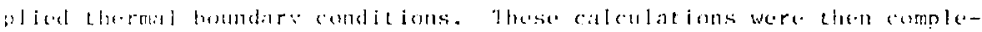

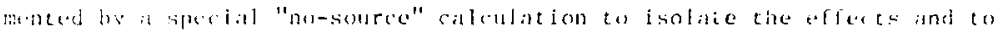

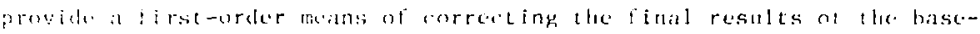

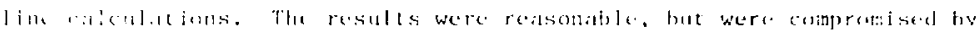

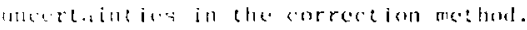

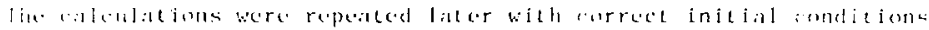

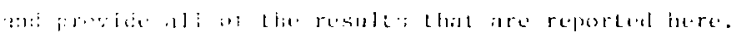

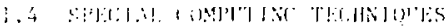

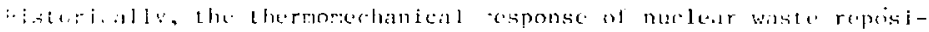

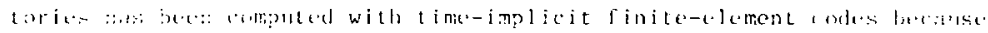

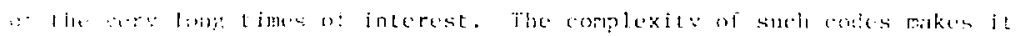

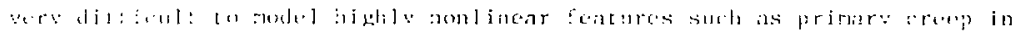

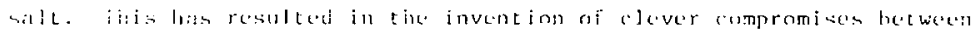

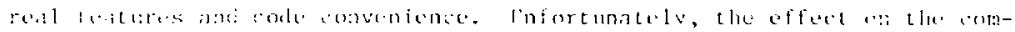

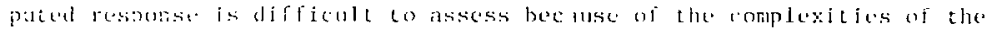

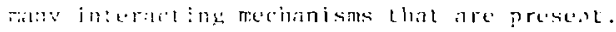

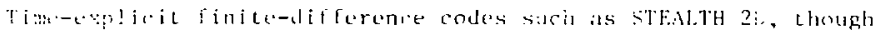
ant cometrained by andel complexity, have been expensive to emplov beciasc a: lik shall mechenical time steps associated with numerical stabilit: in!s constraint has been relaxed bv recenty developed tech-

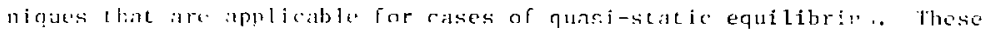

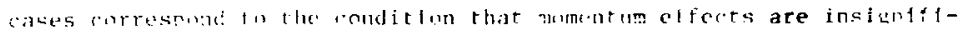

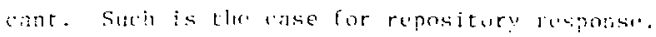


The first of these techaiques is called "pseudo-timc scaling" and is presented in Reference 2. Briefly, tt assigns a different clock to each mass point in the grid to unfold the mechanical motion. The pseudotine. scale of each clock is oprimized such that each mass pojnt alculerate: :oward local stress equilibrium as vigorously as stability allows. Thus, the stress-strain fields are constantly and vigorously driving towird equilibriun in response to the thermal expansion as the temporature field unfolds on tise real time scale. The vigorous mechanical mot ion touard equilibrium is desirable. However, the wass points tend to coast through and oves shoot their equilibrium posilions due to their enhanced momenta.

Dyaamic relaxation, also described in Referenc. 2 , is employed to damp the pseudo-mechanical nscillations. In particular, if the assicned dasping coeficicient corresponds to the lowest natural frequenry of the system, then the osciilations are critically damped and the rectanical response is ontimized with respect to following the true equilirtis: foit unfolis in space and reas time.

These teciniques have here inciuded in a siperial version st the STEALTH $2 \mathrm{D}$ code and have been demonstraed in sale repostory studies.

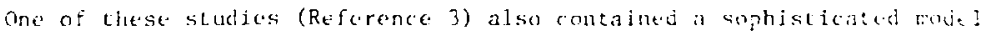

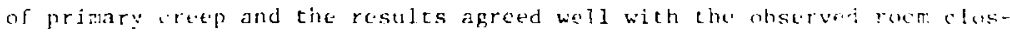
ures (Reference 4). Another study (Reference 5) asamed an (xiteried repository for three cases of wase levels. There were no toperimental diati for comprison, hut the reqults agresd well with two neber contractors performing ropalion calculations. Lnfortunatedy, orep was not inclacted and theste dalculations provided only cieranolastis simulations.

Creep ins present in all hut one of the ralculal iuns of the prosent study. It was turned of during a rereat at the ijhin rase to guntiay

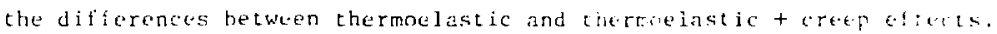
Flasticjty was purposely excluded in all of tisese colculations ay aro input parameters that produred a very high yield surface. 
The existing STEALTH primary creep model was employed with the roefficients adjusted to give a reasonable fit to the experimental data of Reference 6 . The model is described in detail in Reference 3. A juick overview is presented next. Let $e_{x} \cdot e_{y} \ldots$ he components of the Cauchy strian teasor and " $x$. " $y$, ... he components of the stress tensor and define:

$$
\begin{aligned}
& S=\sqrt{\frac{1}{6}\left[\left(a_{y}-y^{2}+\left(c_{y}-z_{z}\right)^{2}+\left(e_{z}-\tau_{x}\right)^{2}\right]\right.}+c_{x y}^{2}+\sigma_{y z}^{2}+r_{z x}^{2} \\
& e=\sqrt{\frac{1}{6}\left[\left(e_{x}-e_{y}\right)^{2}+\left(e_{y}-e_{z}\right)^{2}+\left(e_{z}-e_{x}\right)^{2}\right]+e_{x y}^{2}+e_{y z}^{2}+e_{z x}^{2}}
\end{aligned}
$$

Thus, $S$ and $c$ correspond to the usual definitions of the soranc invariant

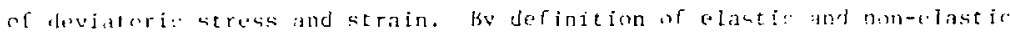
strilin.

$$
\dot{s} / 2 .=\dot{e}_{\text {elastic }}=\dot{c}_{\text {total }}-\dot{e}_{\text {plastic }}-\dot{e}_{\text {creep }}
$$

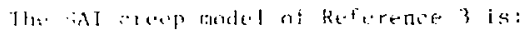

$$
\dot{i r c e p}_{\text {crop }}=a\left[A S^{c} F(a, b)\right]^{\frac{1}{a}} / e_{\text {creep }}^{\frac{1}{a}-1}
$$

where " is the absolute temperature and $A, a, h$, and $c$ are materinl parameters with a l for primary creep. The Reference 3 creep model temperature dependency is $F(A, b)=0^{\dot{D}}$. In the present study, $F(A, b)=\exp [-b / a]$, which gives equally goorl results compared to experiment and is more plausjble by di location theory.

The Prandt-Reuss flow rule completes the link required for insertion ot crup into the code,

$$
\dot{e}_{i j \text { creep }}=\dot{e}_{\text {creep }} \frac{o_{i j}}{s} \text {. }
$$


The sinnltaneaus solution of the set of equations fnvolves highly nonlinear cerms and it was necessary to employ a fourth-order ktonge-kut ta method with subcycling to provide high accuracy and to provide ... ... contral for trade-ofi against computing conts. 


\section{SECTION 2}

COMPUTATIONAI, SETUP

\subsection{LAYIRS ANI MATERIAL PROPERTIES}

The sitc stratjgraphy was supplied b: Sandia Laboratories and was idealiod by asioming homogeneous isotropic materials and blendjug thín lavers into marolayers as shown in Figure l. The assumed thermoulastic propertis of the materials are given in Table 1 . The properties of the ummi.sed materials correspond to those of Reference 5, which are hindhouk

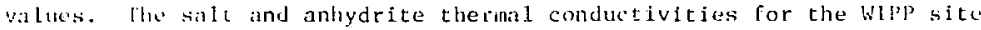
were wheine th trom Reference 7. The mixture properties were constructed from Llie pure miderials by standard means. Briefly, the pressure changesi were expecterl to he of the order of the overburden so that densitu ithangus waic bo small. Bending stresses, generated by thermal expan;ion in the prosence of a temperature pracient, were expected to be very important with respect lo uplift shape and potential mechanical railure, These consideraLions are consistent with L'tating Young's modulus and Poisson's atio ats the doninating elastic moduli. Their average values, obtained by volume weightirg, were chen used to construat thi average values of bulk and shcar moduli i $i$ the mixed materials of Table 1 . The remaining mixture profertics were con tructed from simple volume averagos.

\subsection{CREEP MODE. PARAMETHKS}

The paramelats of the creep model (p 4$)$ were lit by trial ind error to triax experimental creep curves from Reference 6. Tests of 50 to 500 iours duration were used to minilize the large creep rates observed in, riort axperiments. The resulting parimeters were:

$$
\begin{aligned}
& a=0.4655 \\
& l=4100 . \mathrm{k} \\
& c=3.0 \\
& \Lambda=3.1386 \mathrm{E}-20 \mathrm{~Pa}^{-c} \mathrm{~s}^{-a}
\end{aligned}
$$




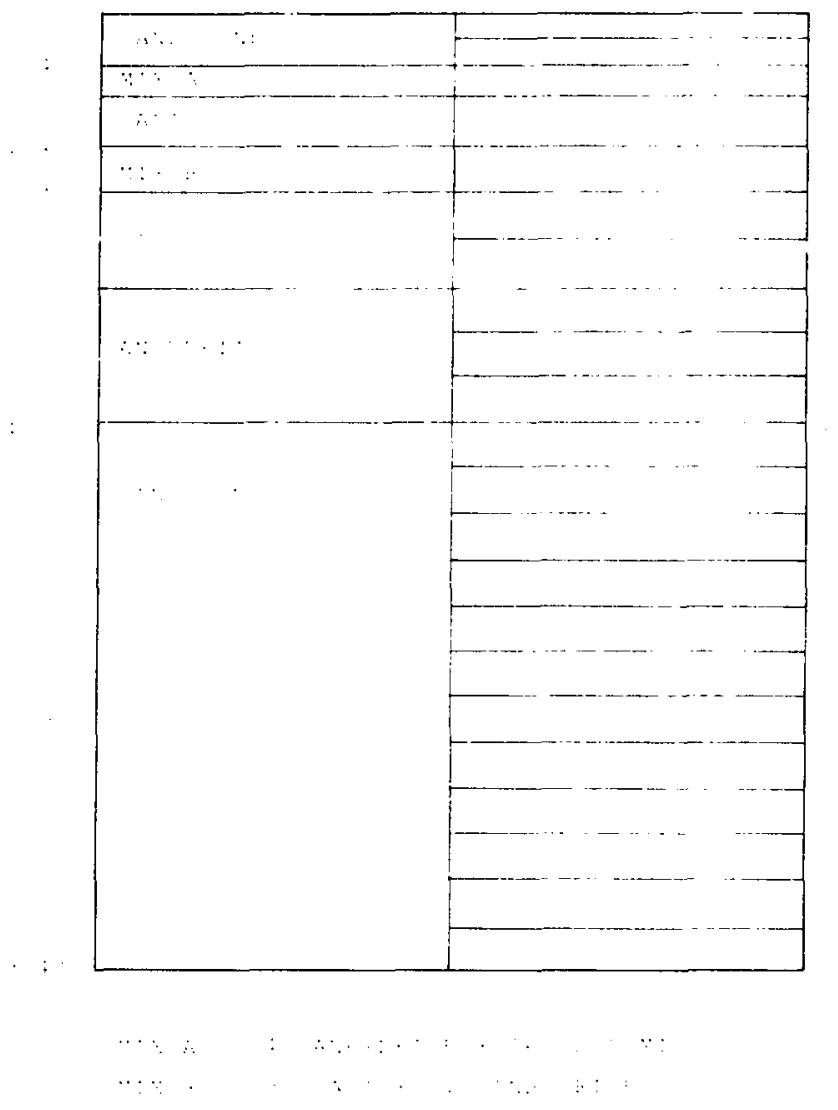

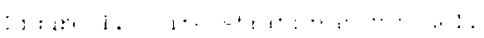


TABLE 1. TIFRYOELASTI: PROPERTILS

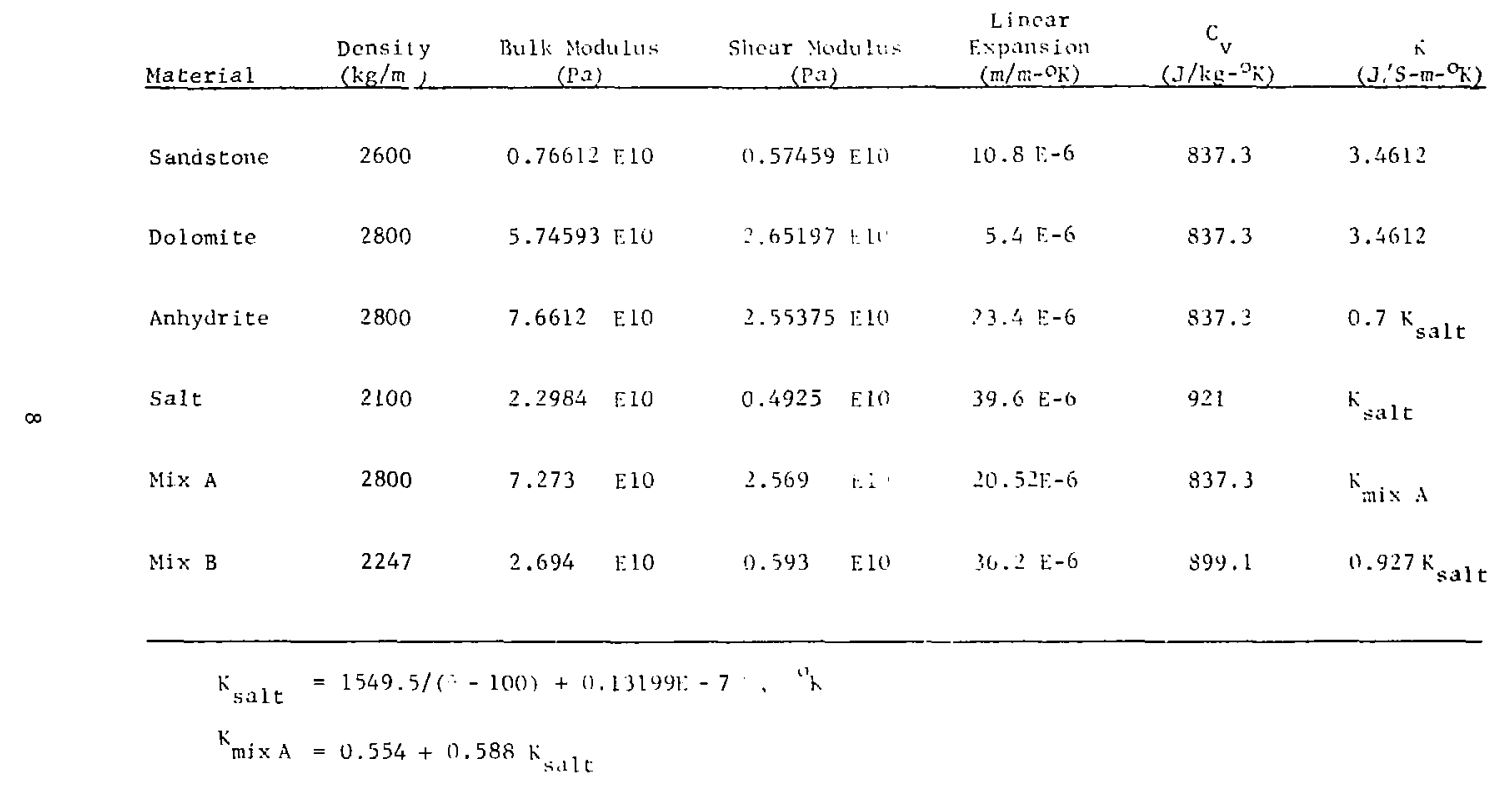




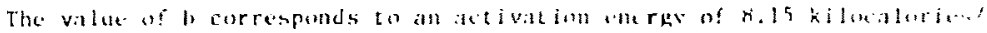

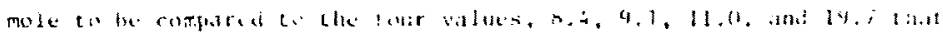

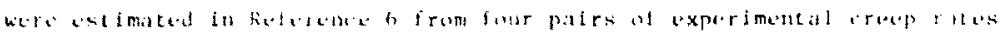
int this ialt.

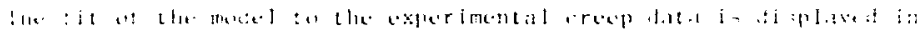

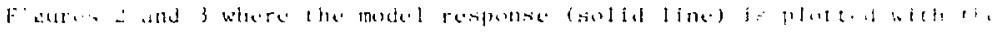

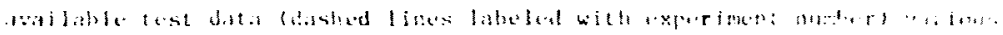

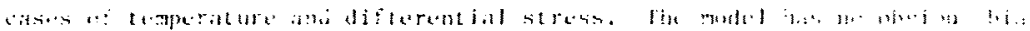

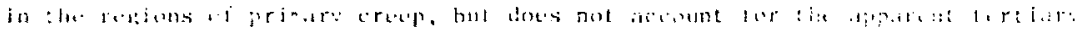

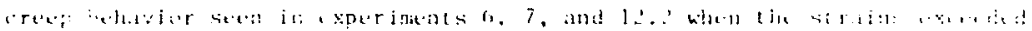

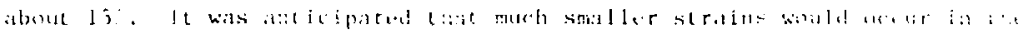

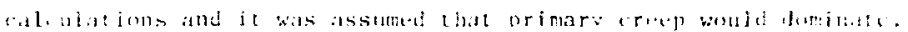

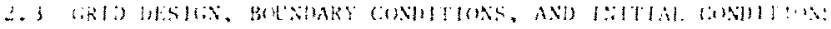

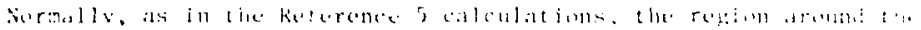

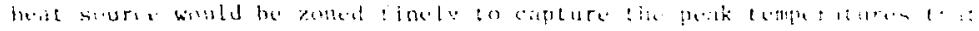

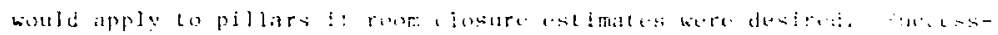

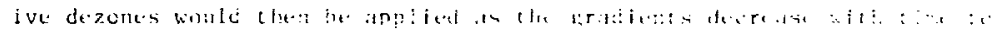

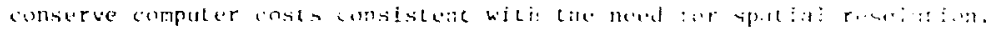

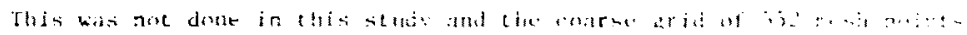

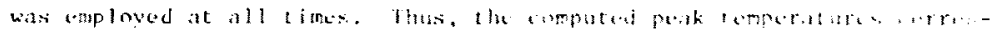

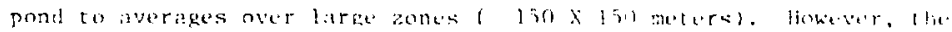

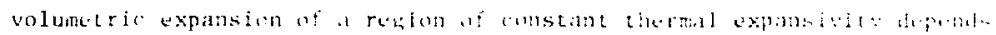

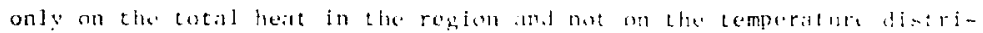

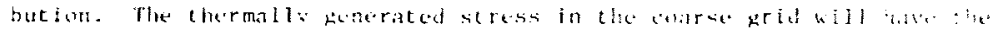
correct antal averibes.

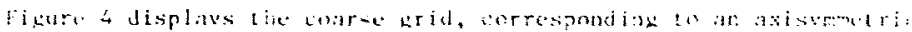

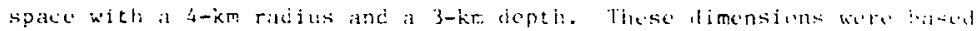

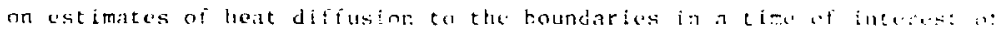

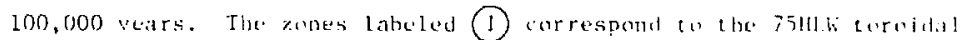

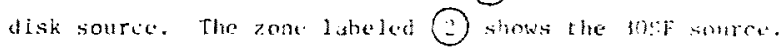




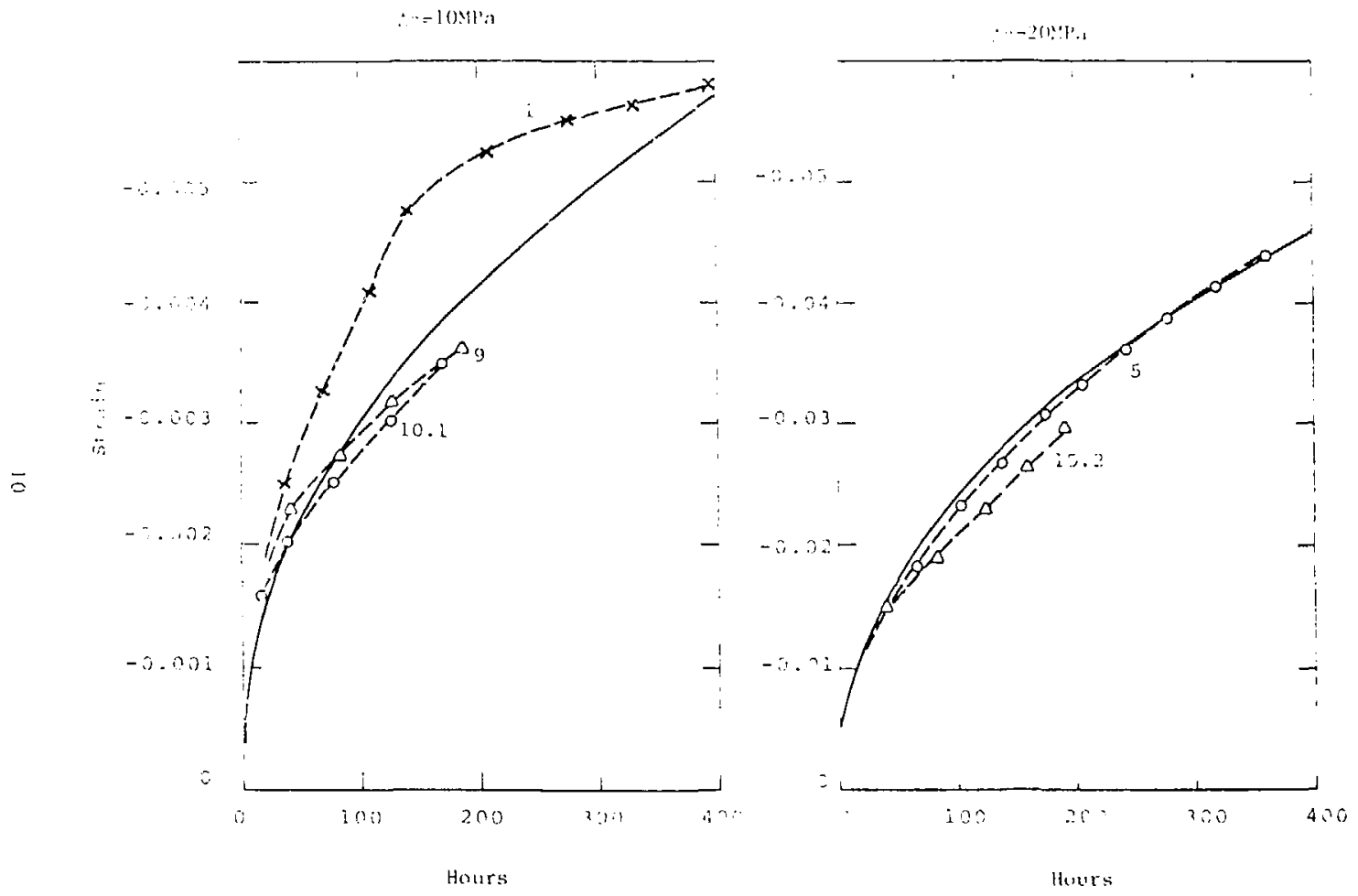

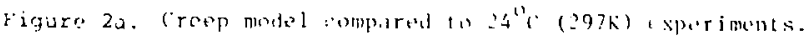




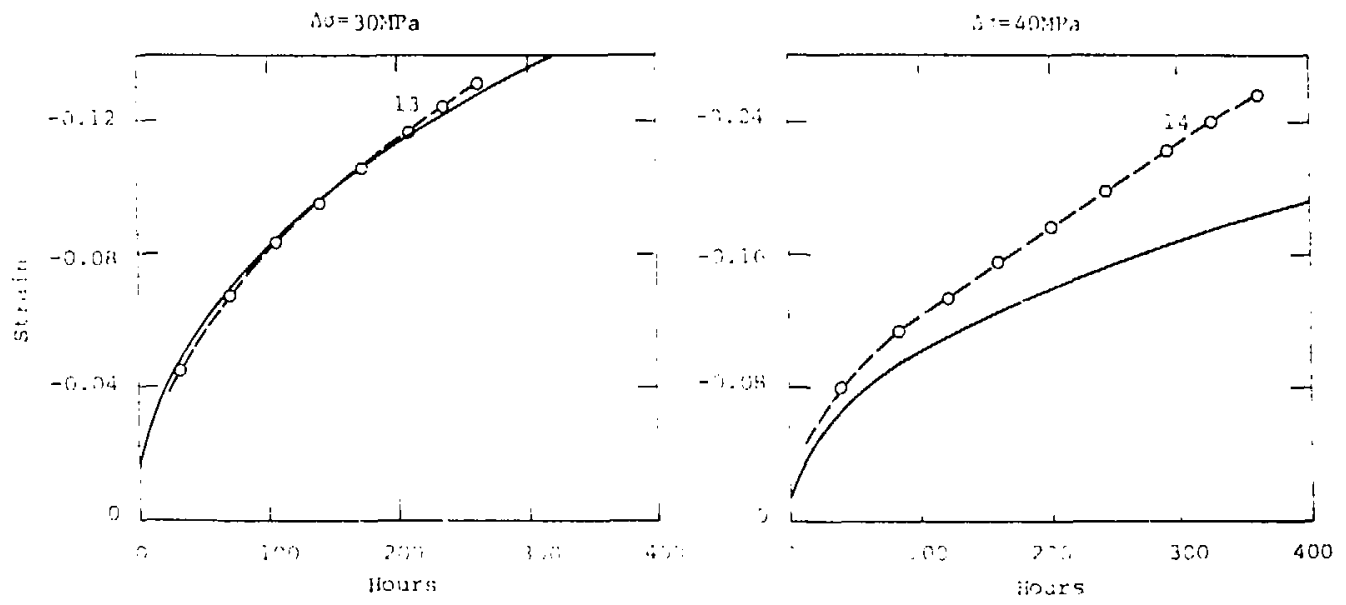

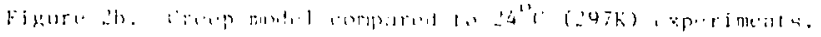




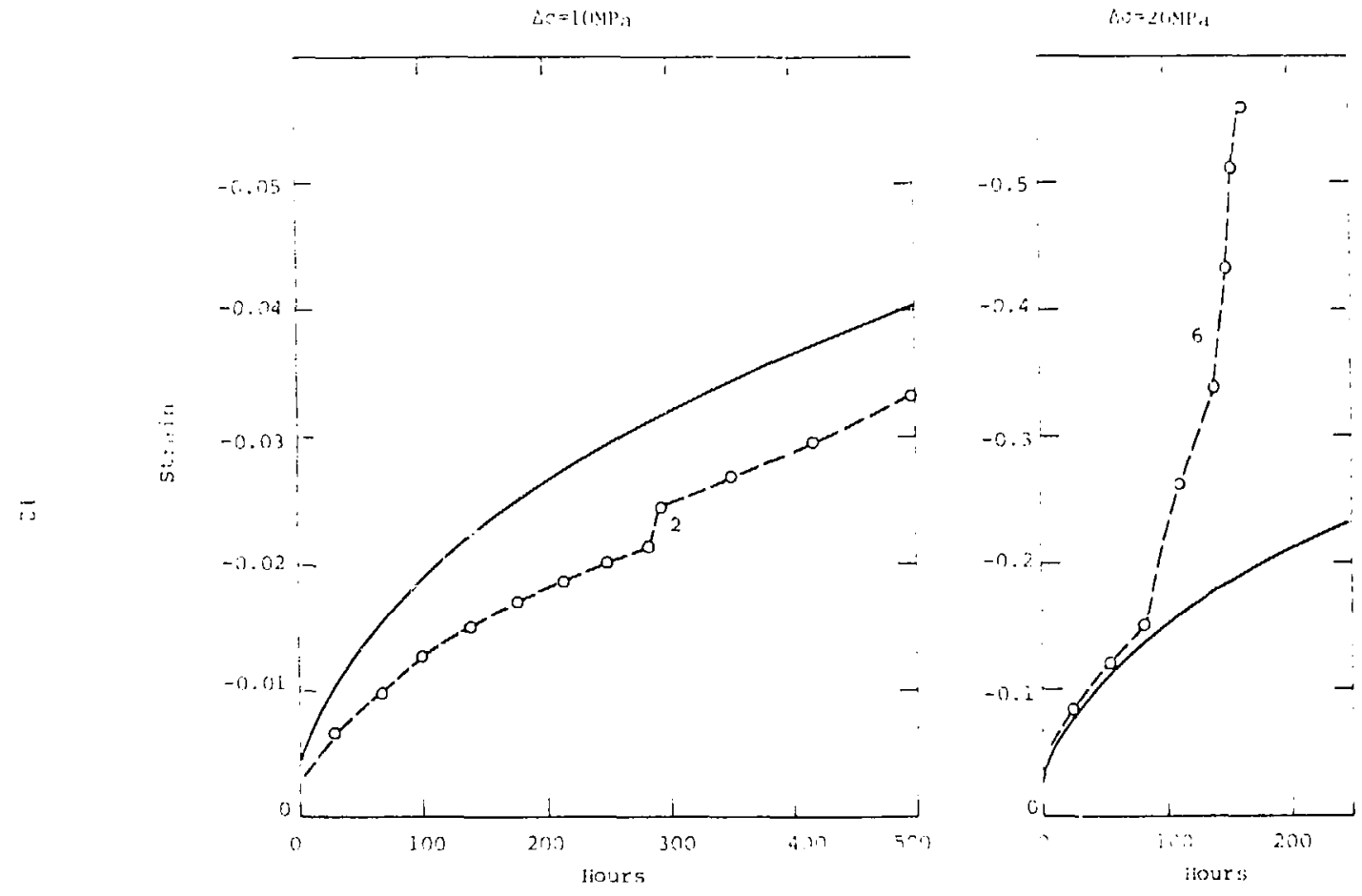

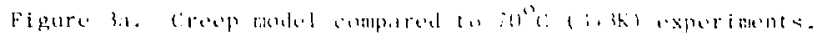



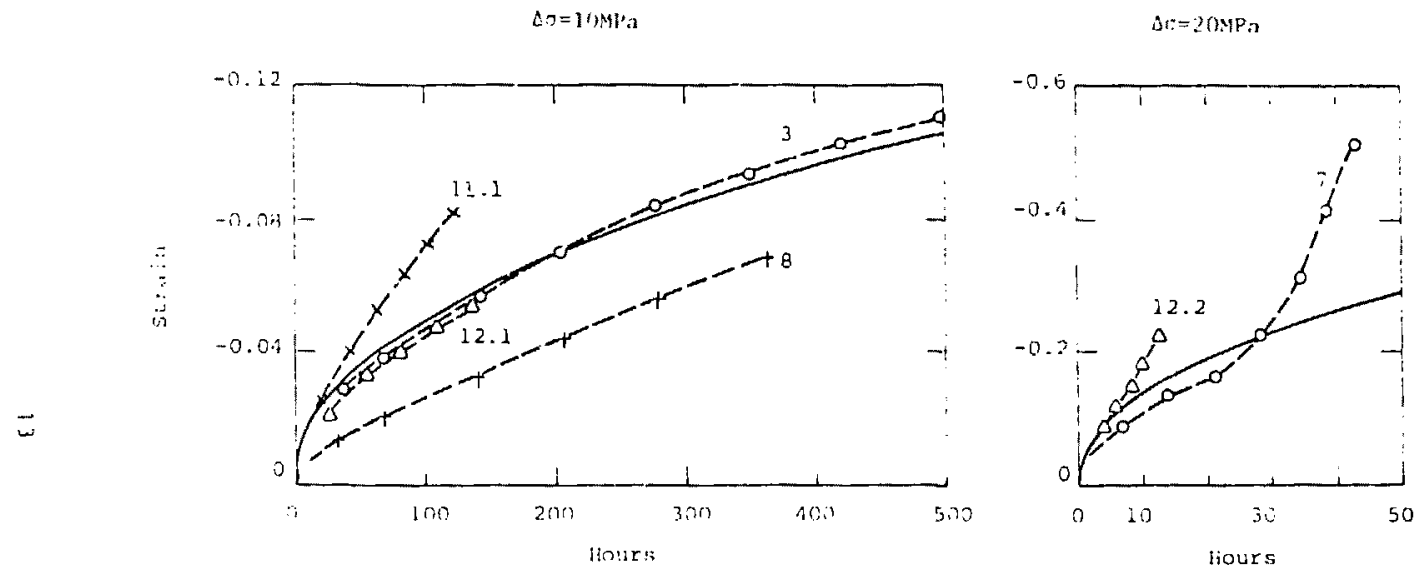

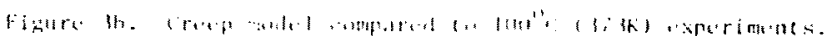




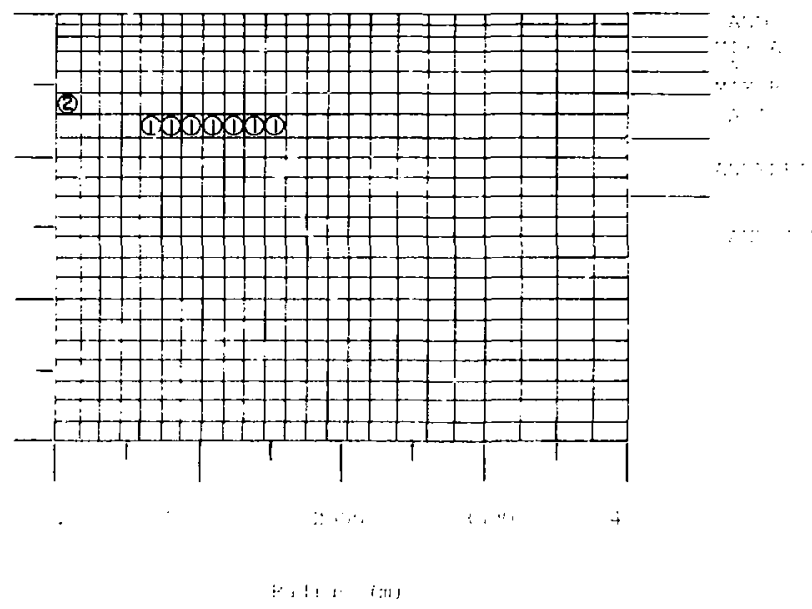

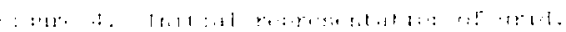


The stresis boundary cordit innt wert:

- :ilrtac-

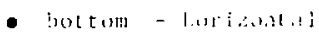

b side - vertacid rulicr

Ihe seleceded thermal houndary conditions inte:

- surface - Lsothermal at 2$]^{\circ 1} \mathrm{C}\left(/ 1^{\circ} \mathrm{F}\right)$

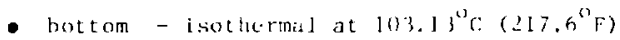

- side - is.ithermial in time with as deptir dependen... consistemt w: th the surtiace ard bot lom temperaturess and thermal equilibriatu

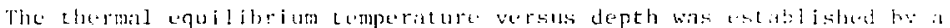

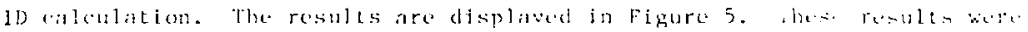

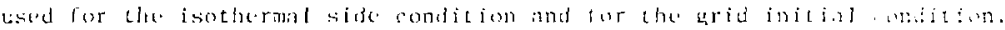

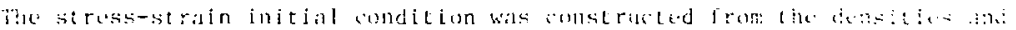

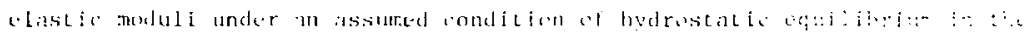

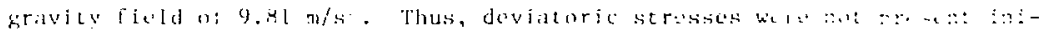
tial $1 \mathrm{v}$.

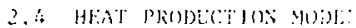

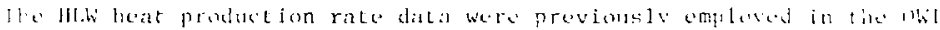

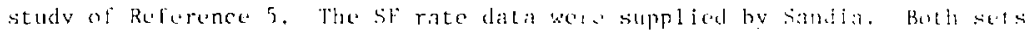
of data were normil ized to 1 wate/are at the ton-voar cooling time and then scaled as appropriate for the baseling calculations. Figure h displavs the normalized power versus time for lhese naterialis. The integrals of the powes surves give tinc heat reloased. Tlese are shown in Figure 7. 


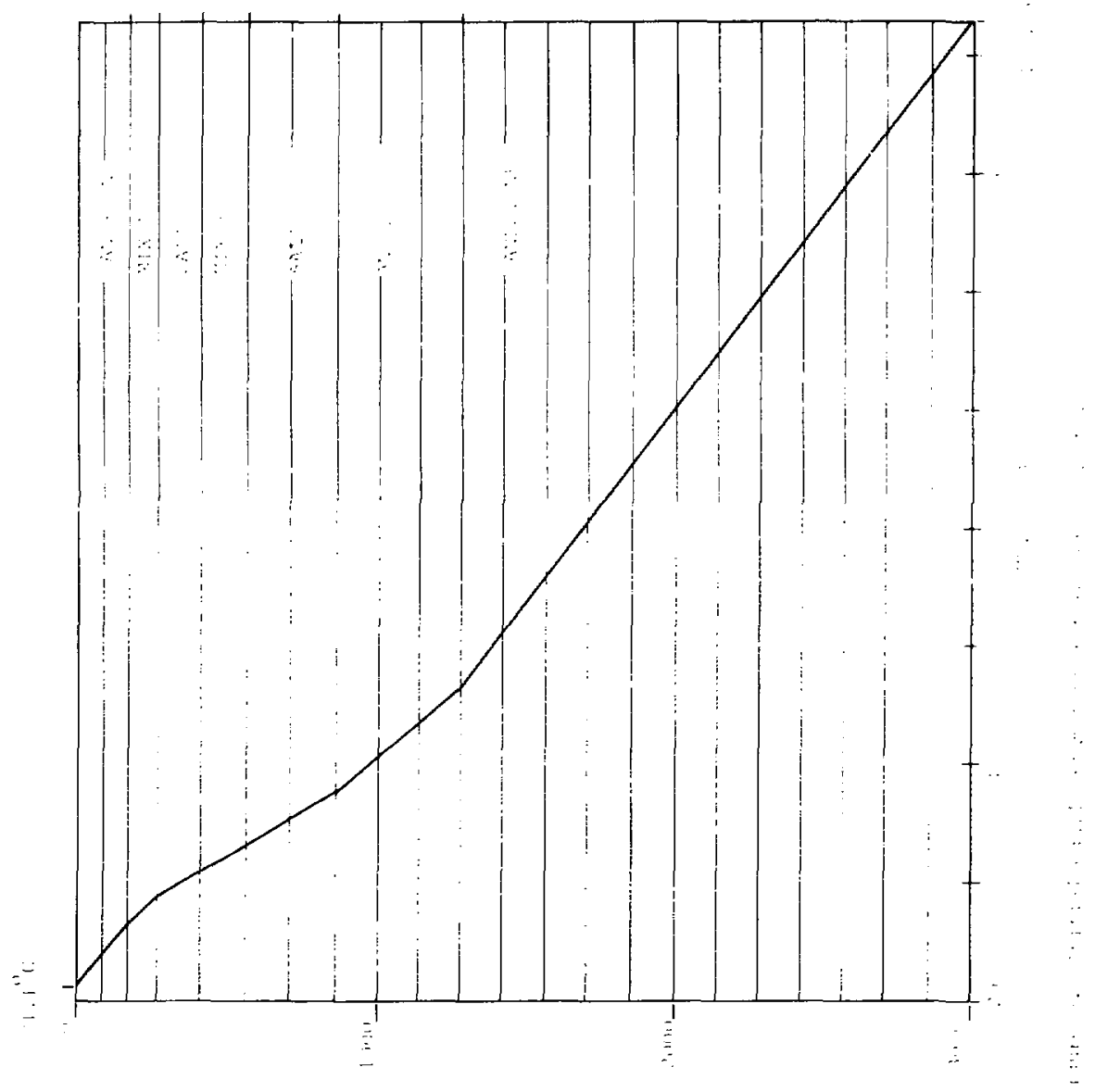

(u) $11+\vdots \cdots$ 


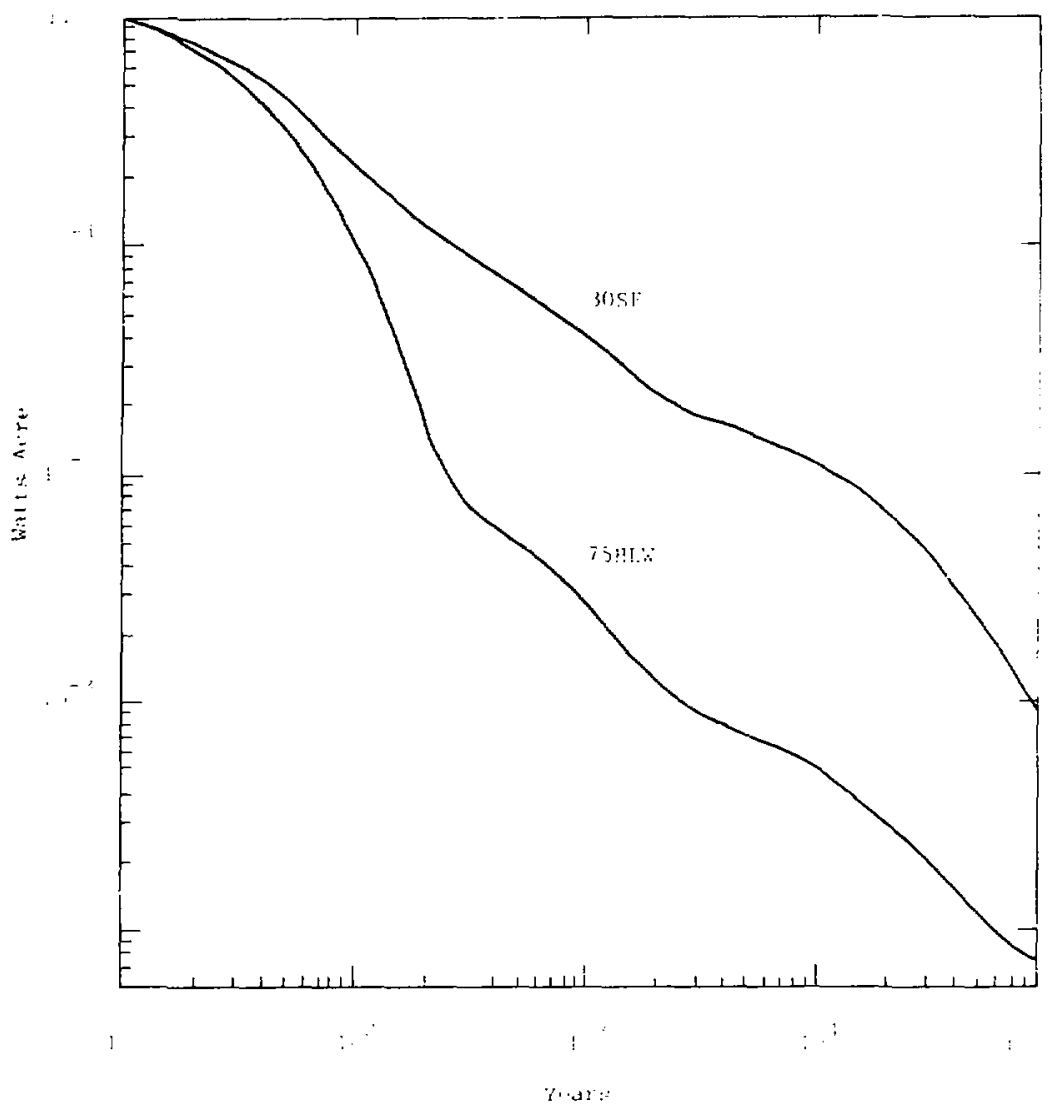

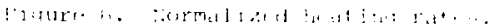




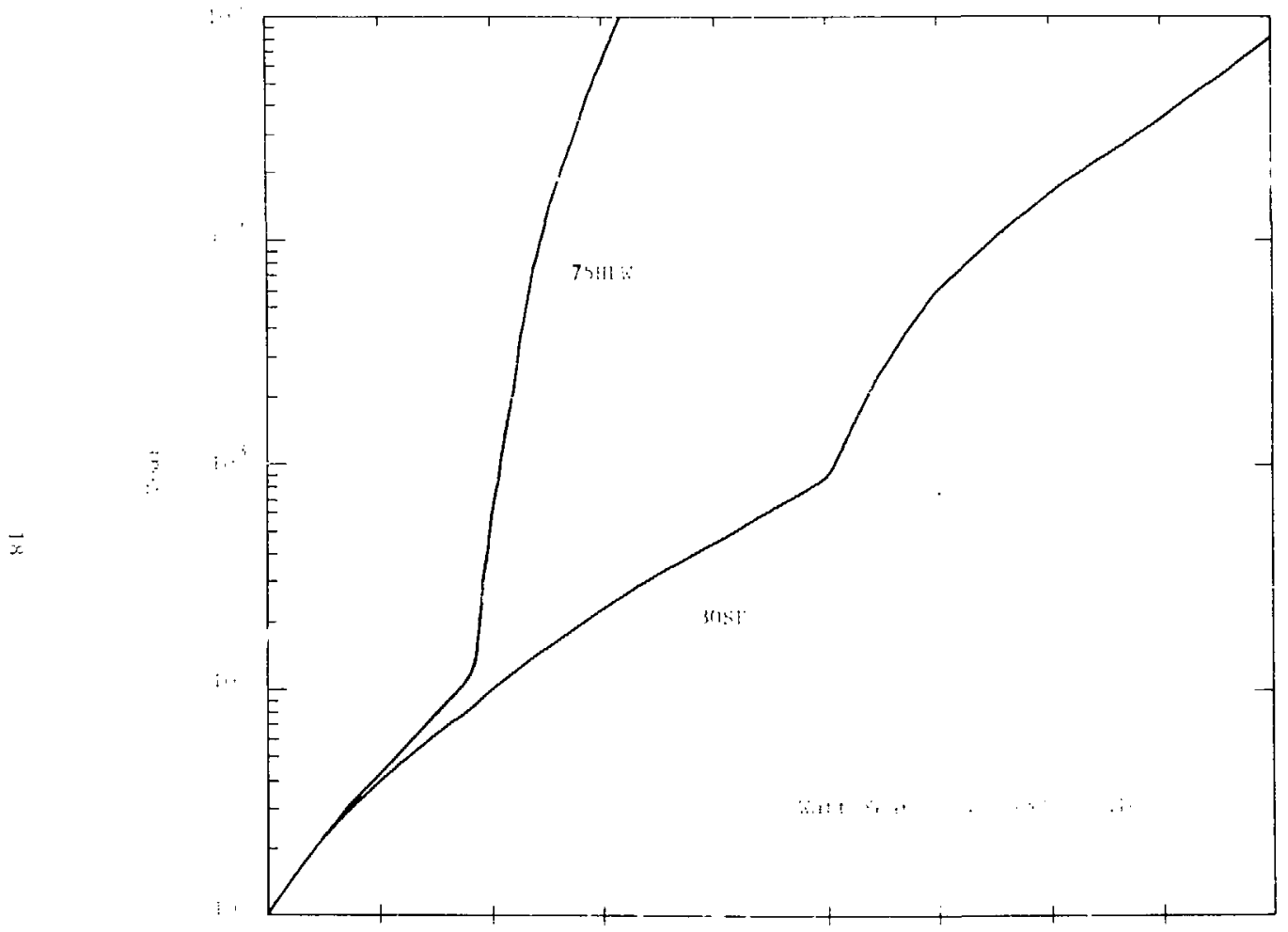

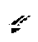




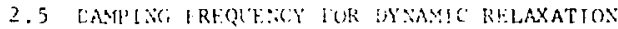

Tho damping frequency, $\iota_{3}$, required for sptimum das. ing wa r.scabli-race

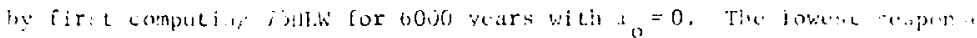

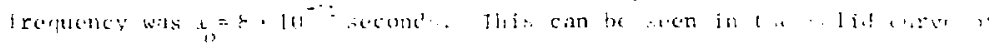
Figure 3 . which shows tice vertical motion at the surface ?' " radiu."

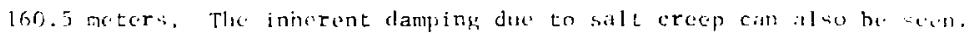
An inpele value of $t_{0}=8 \times 10^{-3}$ would give critical damping if cren arere not prosint, but wili ivi overdamping for our cilios.

The [a]lulation wite recomputed with values $1=6.3 \times 19$, and $3.15 \times 10^{-\cdots}$. The result of the lateer is cinom as the dasted curve ol

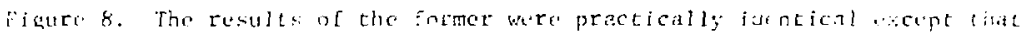
the joe on the [irt upsing wat misting.

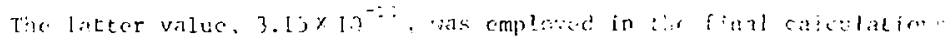

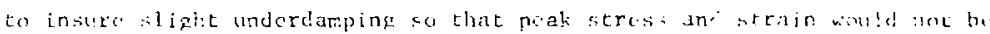
linticrestimated. 


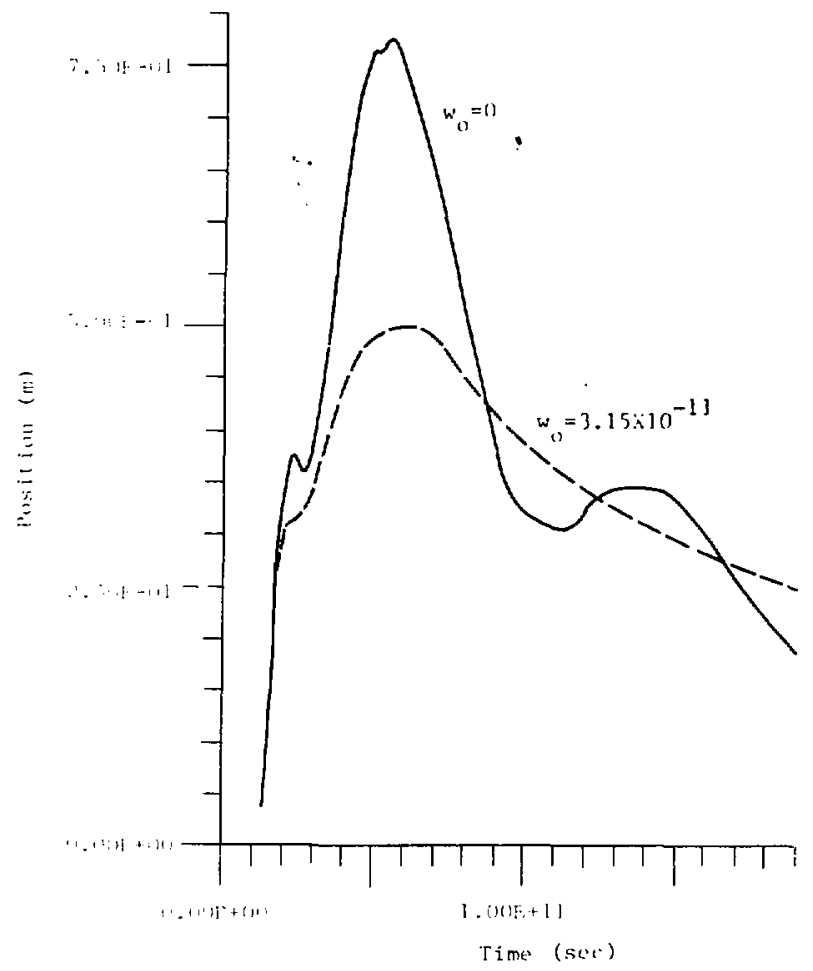

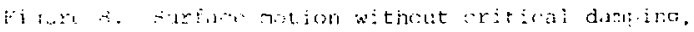


SECTION 3

COMPUTATIONAL RESLLTS

\section{L CUSPLTER PI.OT SYMALIS}

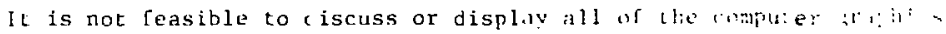
ior the calculations. The text will show selected plots pertinent to the discussion. The plot data are in SI units with the exception of temparature, which is in degrees Centigrade. Table 2 provides a concordancs n: symbols. The zone-centered quantity locations are misleading. They are labeled by $I, J$ and XPN,YPN on time history plots. These are not trut Incations. The true locations are $\mathrm{I}-1 / 2, \mathrm{~J}-1 / 2$ and $\mathrm{XPX}-\mathrm{i} y / 2$, where $x / 2$ and $\therefore y / 2$ are the zone half-width and half-height.

Figure 9 locates and indicates typical plots. The points showe in: the grid zegion locate various time history plots. Profile mi contoni plots at rixed time are also noted.

\subsection{HEAT AID TEMPERATURE RESULTS}

The heat balance versus time is shown in Finure lo for 30s\% and 75HLW. The heat input curves are consistent with the firure 7 curves when they are appropriately scaled. The srale factors are:

$$
\begin{aligned}
& 30 \mathrm{FF}:(30,000 \mathrm{~W} / \text { acre }) \times(20 \text { acres }) \\
& 75 \mathrm{HLW}:(75,000 \mathrm{~W} / \text { acre }) \times(1717 \text { acres })
\end{aligned}
$$

The difference between the heat input and grid heat corrosponds 6 the loss through the top surface by the assumed isothermal houndary cundition. The loss through the side and hottom surfaces wati insignifivant.

The peak grid heats occurred at 1500 years for $305 \mathrm{~F}$ and at 1000 years for $75 \mathrm{HLW}$. It will be seen later that the peak uplifts occul at similar times. 
TABLE 2. I'LOT SYMBOI. COEC:AF, DANCH:

Plot Symbol

TH, T'M:

$I^{\prime} P:$

Xes

[1,5 5

PRII

$\because 1$

$7: 41$
Mcan ing

Tinc $($ scoc $)=$ vate $\times 3.1536 \times 10^{\circ}$

Depti (n) o[ point at 1, J

Radjus (m) of noint at $\mathrm{I}, \mathrm{J}$

I) i.tance (m)

Pressure Pat it rone center $1-1$, J-?

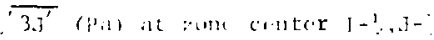

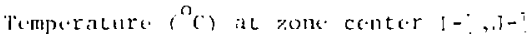



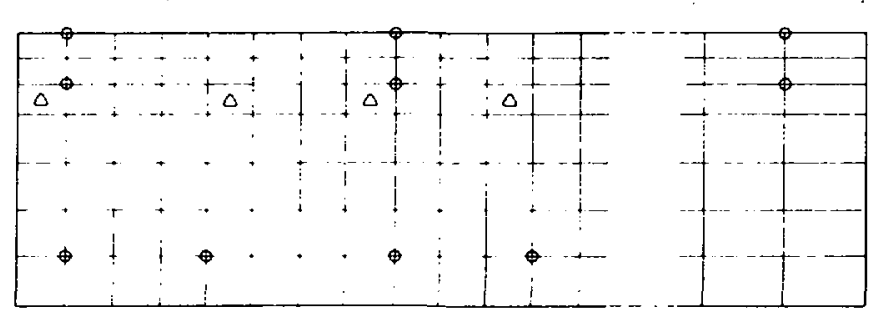

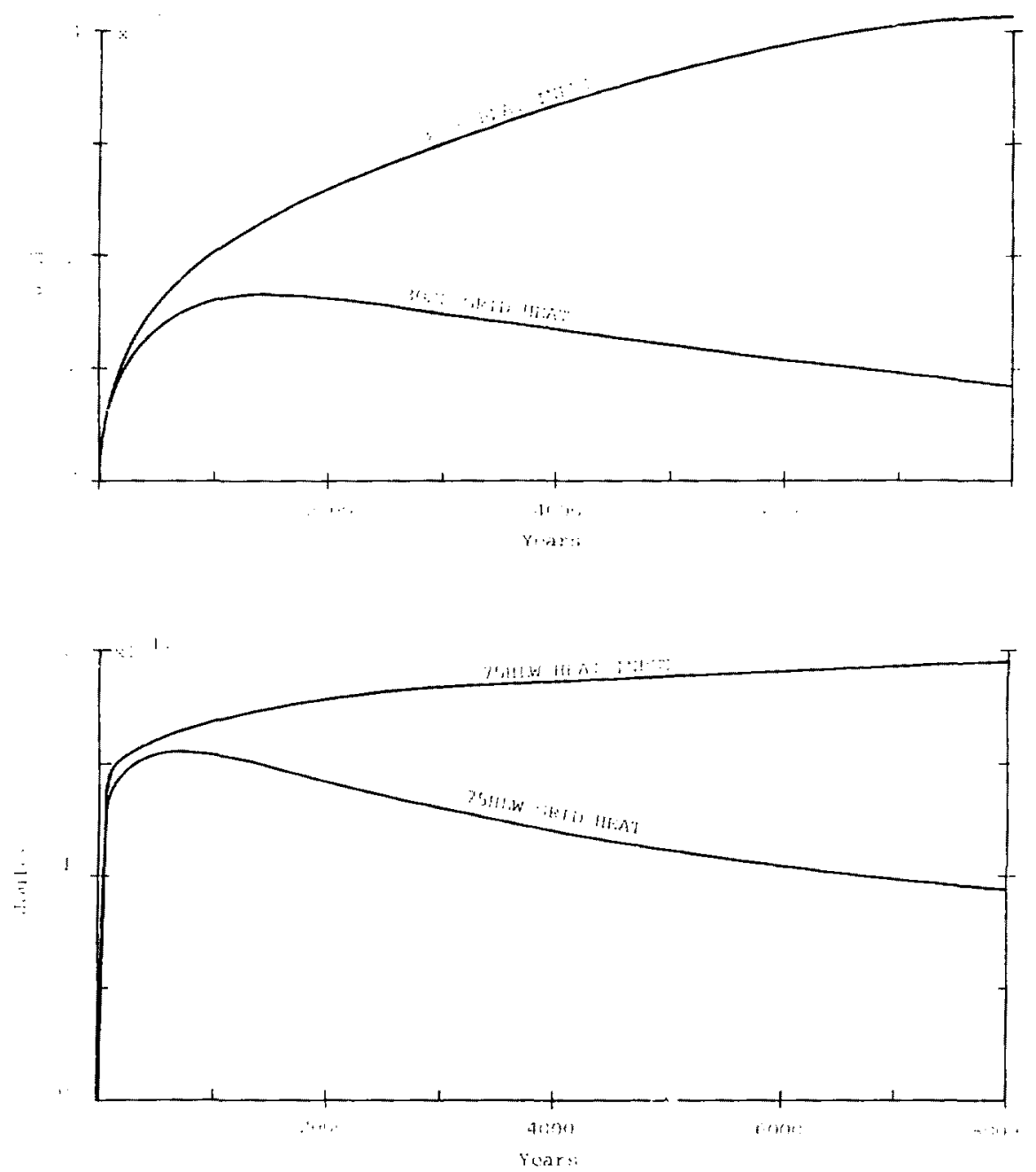

Figuro lo. Heat halares fsoe text.). 
Temperature rise versus radius at selected times and depths are shown in Figures 11 and 12 for 75HLW and 305F. The lowest depth in each of these figures corresponds to the repository level. The earliest time shown is 500 years. The maximum temperature rise in the repository level was abiut three-fold larger than that shown at 500 years and nccurred hefore 80 years. These data are misleading and are not shown because l.1rgu temperalure gradients which cannot be hundled by the coarse grid orour at early times. However, by 500 years the computed gradients cxteni over several zones and the results are realistic.

\subsection{SURFACE UTLIFTS}

Figure 13 a shows the surtace profiles of the final $75 \mathrm{Hl}$. calculations at selected times to 3000 years. The $50-\mathrm{cm}$ peak uplift deiruas.s smoothly after ahout 2000 years, halving at 6300 years and hatuing andis at 16,500 years, reaching a value of $10 \mathrm{~cm}$ at 20,000 .

The peak surface uplift of the final 30SF case was verv small. Figure 13b shows the Einal 30SF profiles at selected times. The Fit:

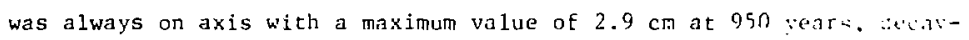
ing to half of this value at 3000 years, halving again at 7 son vears. with a value oi only $5 \mathrm{~mm}$ at 10,000 years.

\subsection{CRELP RESUI.TS}

The generalized creep strain defined in Section l was examined in the $75 \mathrm{HLW}$ and $305 \mathrm{~F}$ grids. The maximum creep strains in both grids occurted at a depth of 788 meters. The maximum in the $75 \mathrm{HLW}$ grid occurred in the innermost source zone, centered at a radius of 662 meters. The maximum in the 3OSF grid occurred on axis, just below the sing soirco zone of jOSF. 

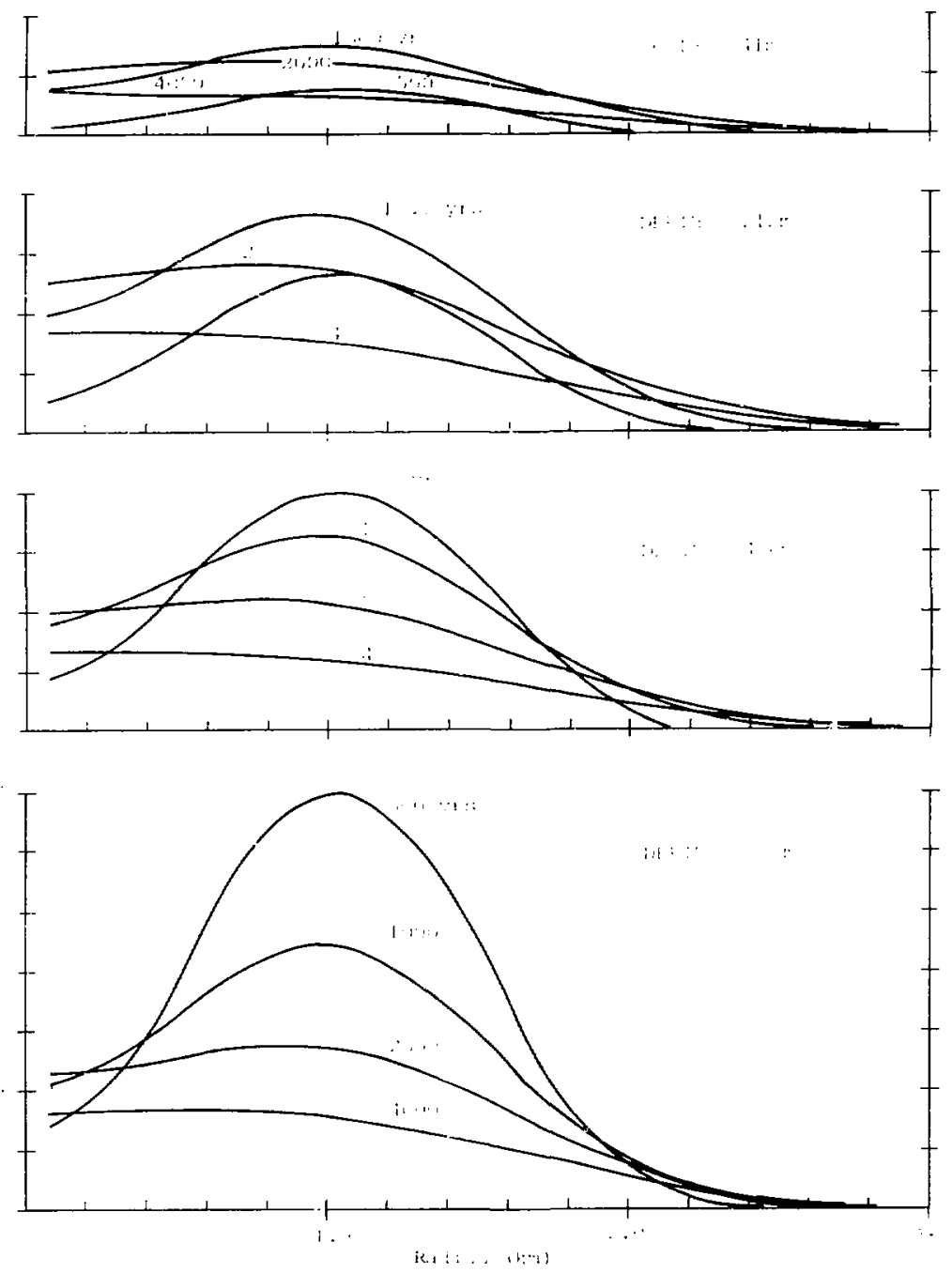

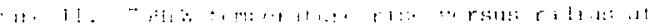

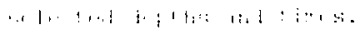



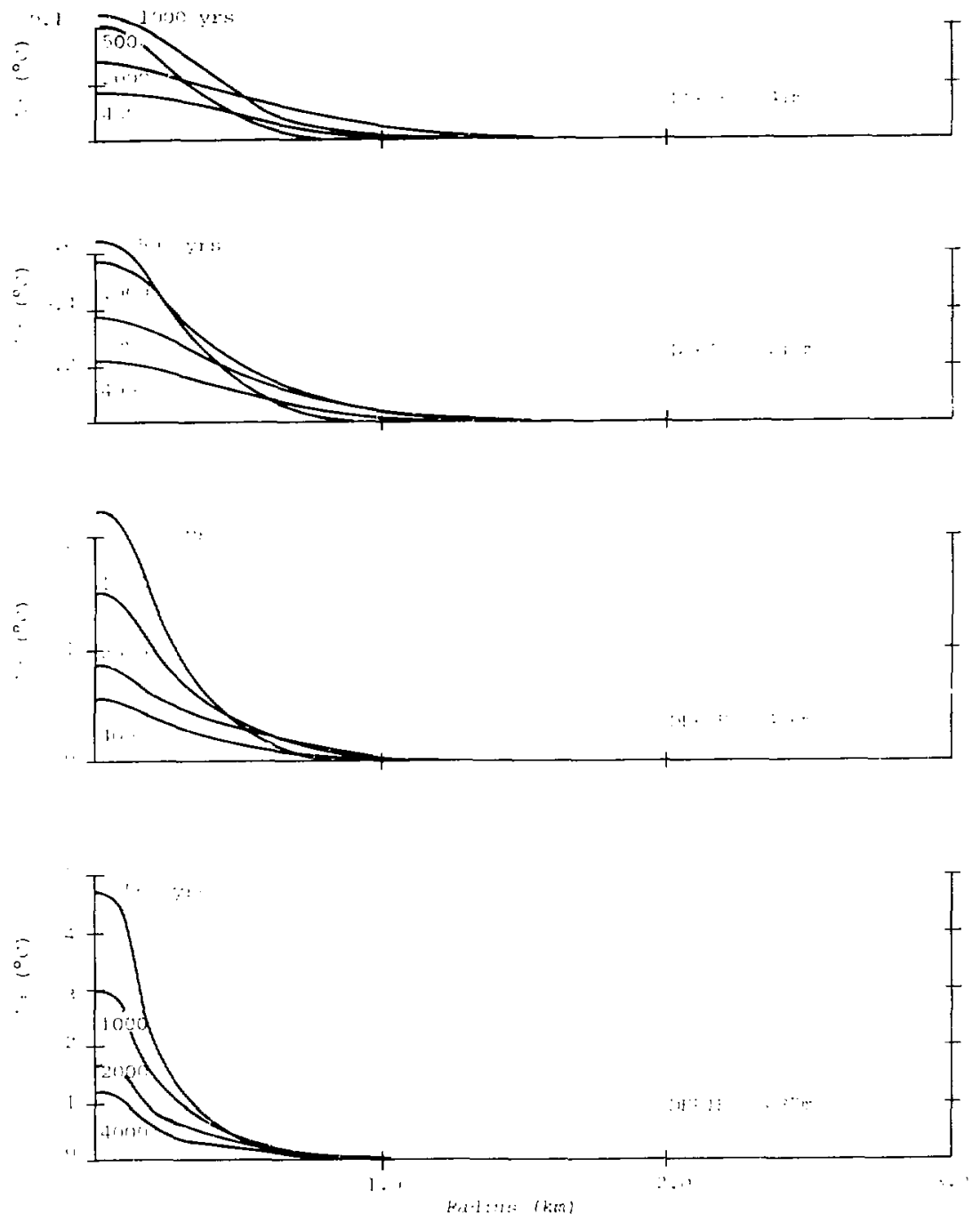

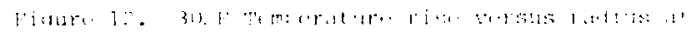

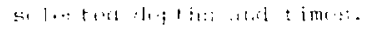


$\stackrel{N}{\infty}$

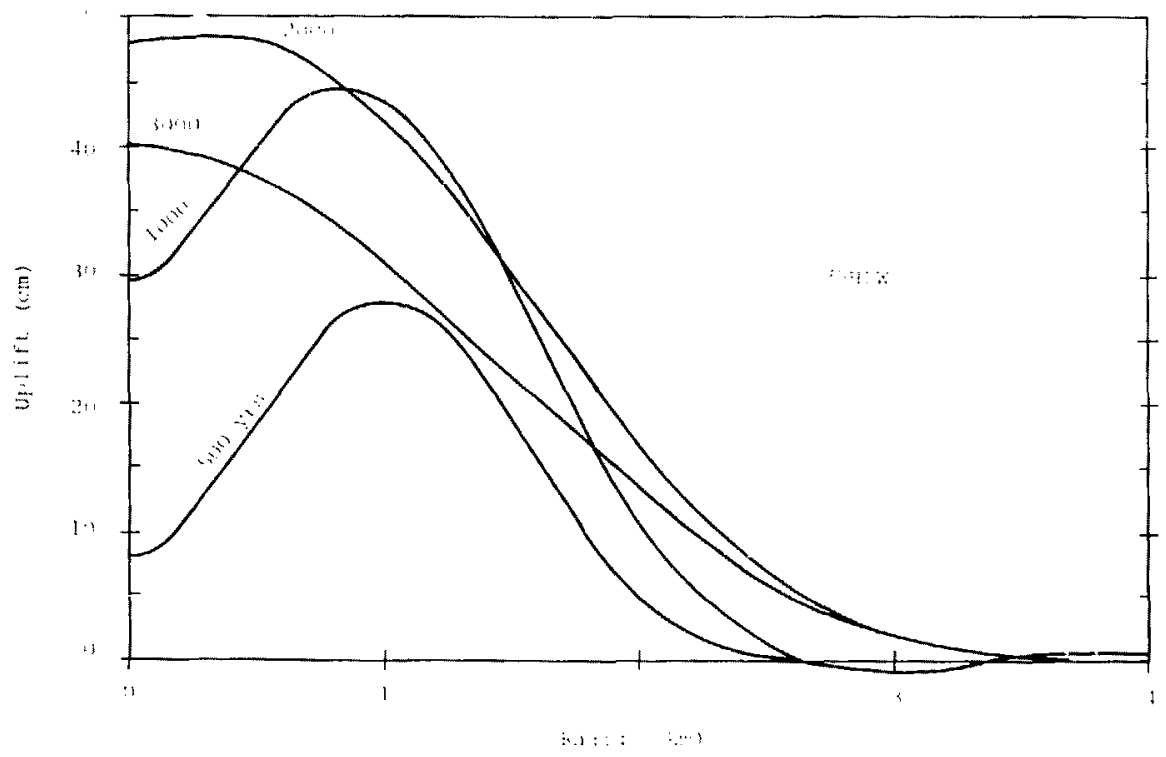

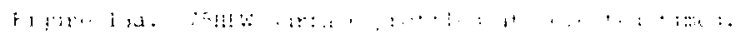




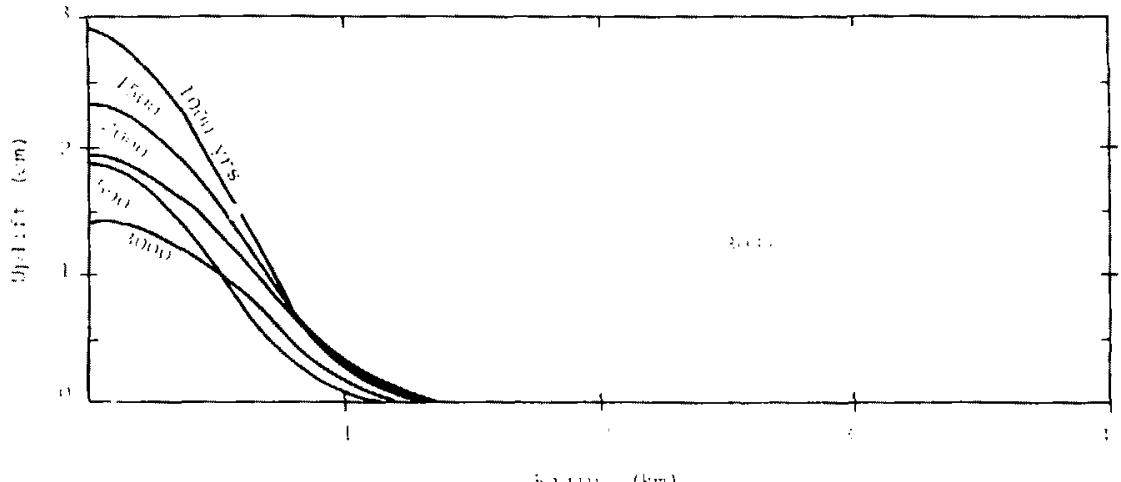

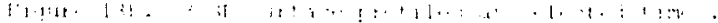




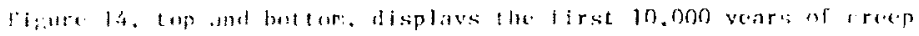

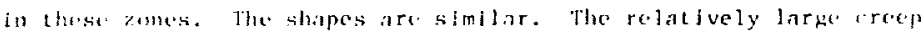
rates in the first lobol veirs are followed by an ever decroasing rat. in

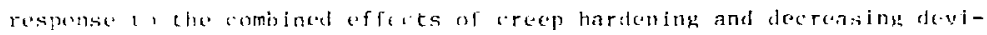

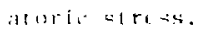

Thoubh the "reep strains were small, the valume of salt was larke and lia effents bere signifiant.

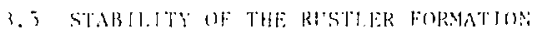

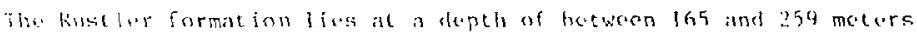

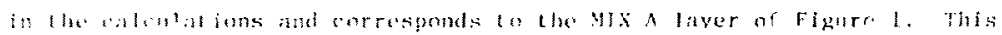

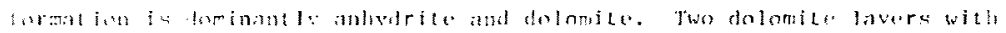

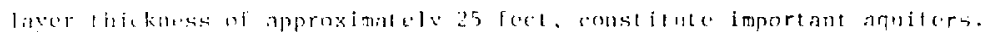

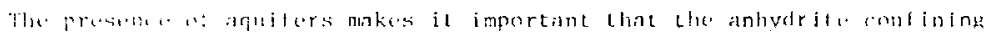

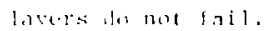

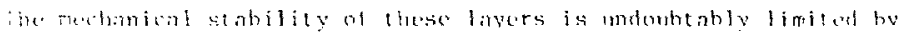

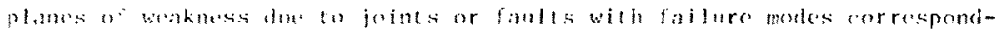

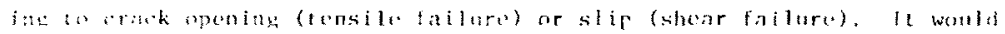
late been expediont to insert tonsile and shear failure models in tho

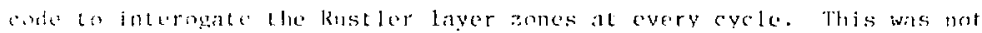
done and it wats positble only to exanine solected regions in space and

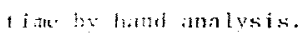

\section{3. Tensile Failure Assessments. The errective stress acting}

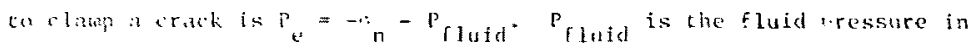
the crack amb in is the rock stress normal to its crack plane. Nogative viluses of a are compressive hy standird convention. A joint with colkesive t will not open provided that $P_{e}+c \cdot 0$. The condition ror tonsile strutul is then

$$
-P^{n} \cdot \text { Pluid }-r_{n}
$$




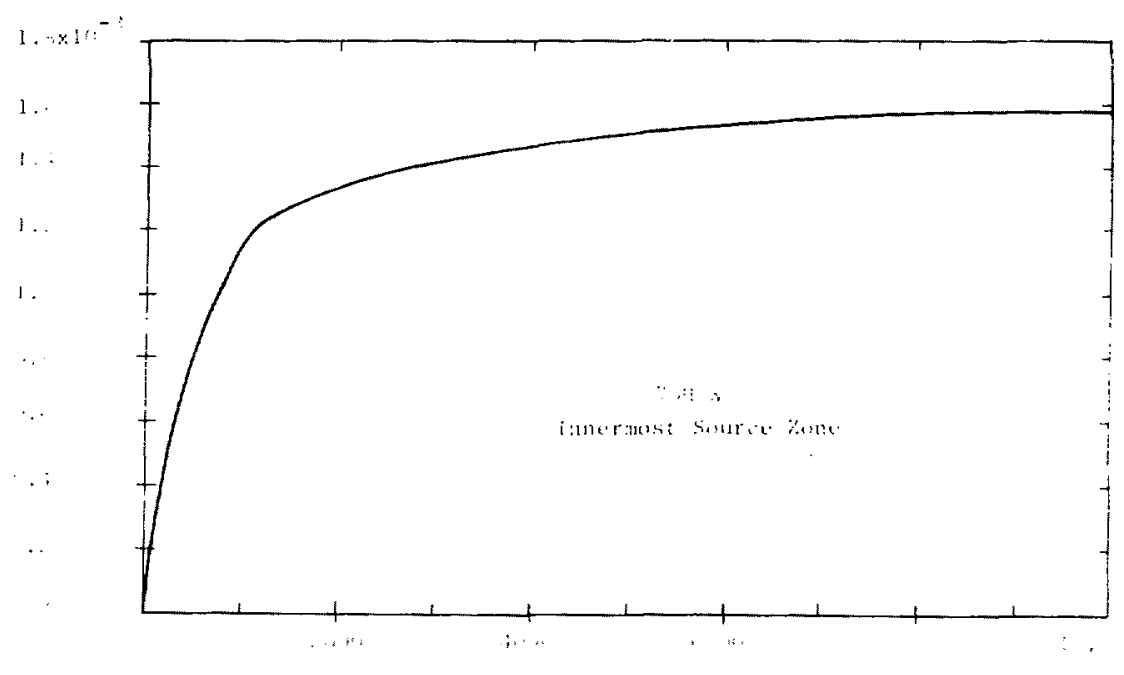

$\because \cdot 1 \cdot \cdots$

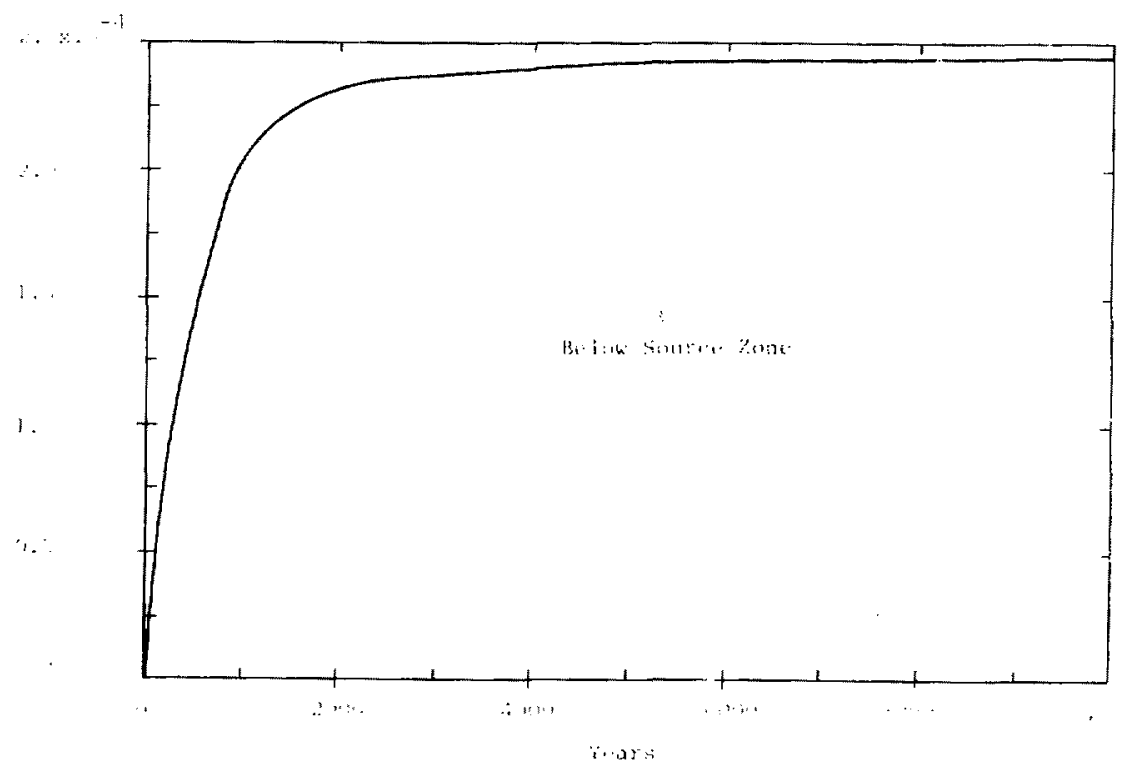

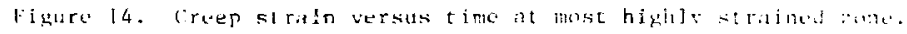


The Eersile assesst. ents in this study used the conservative Milues

$$
\begin{aligned}
& :_{11} \quad=\text { the nost teasile of the three principle stresses } \\
& \therefore \quad=0 \\
& P_{\text {luid }}=\mathrm{P}_{0} / 2=2.74 \mathrm{MP}_{\mathrm{a}} \\
& \text { = half of the Rust ler layer overhurden }
\end{aligned}
$$

the above value of $P_{f l u d}$, nresent in aquifers with ducts to the surface, would rosult in artesian springs.

The zones of the Rustler layer wern :xamined at 1000 years in tensile failure. The principal stress components were deterisilod by rolatini

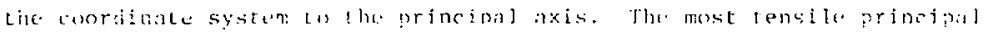
stress was al wyys comprestive with a magnitule that exceeder line hal averburcicn pressure. $P_{0} / 2$. These results are displayed in Figuro dj ror 7j!l!: and 30SF. The curront mean stress, $P$, is also shown.

It can be seen tiut 75 lilw results vary greatly with radias with :lic axis region being the loast compressive. Tle pressurctione historics of 75 Hliv in sppendix 1 show substantial non-teal oscillations in the ixjs resion ( $[=2, J=21)$ that were not well damped by 1000 years. Thus, the near axis dip of stross in Figure 150 is suspect.

The jOSF results of Figure $15 \mathrm{~b}$ show very litcle change from nominal conditions indicating that the $30 \mathrm{~F}$ repository has little effect with respect to promoting tensile failure.

$\$ .5 .2$ Joint Shear Failure Model. Handin in Reference 8 proviles a sumary of the concepts of (l) internal friction for the brittle fracture of virgin rock and (2) sliding friction for slip failure along preexisting crack planes. Byerled in Reference 9 provides sinilar data 「or westerly granite in a series of meticulous experiments involving controlled surface roughess and interstitial water. These studies and 


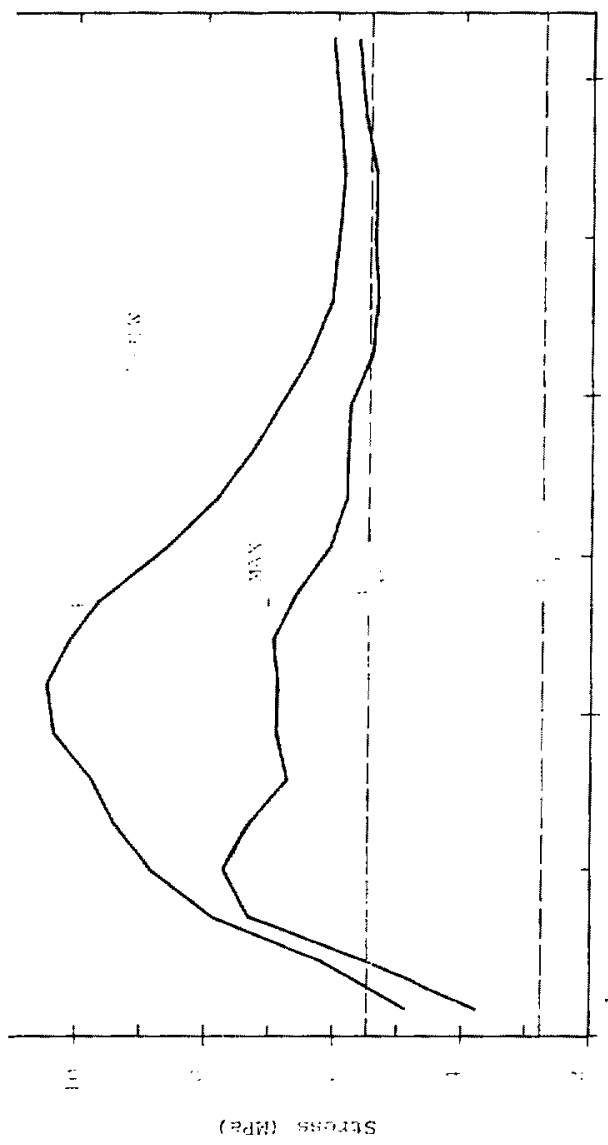

33 


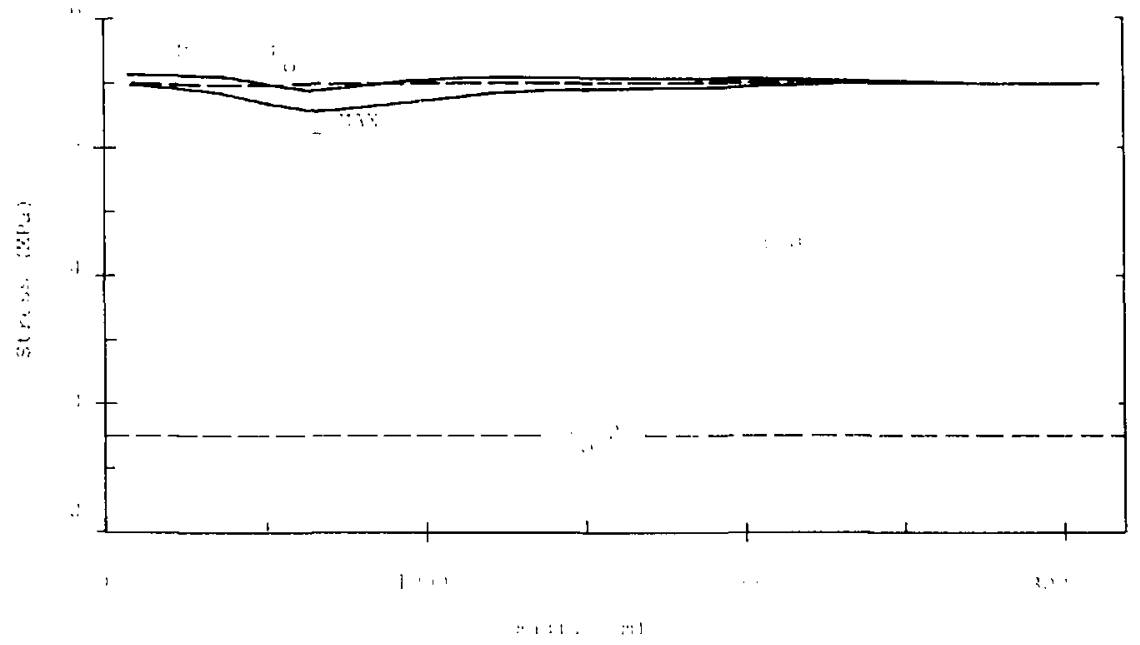

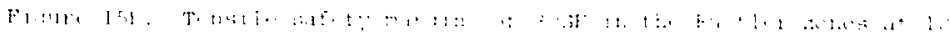
$\because 1 ?+1,1 \cdots 31$ 
others provide an accepted model an slip failure aloms a promist inj: crack that is trikibered wher

$$
r_{p}=:+. \cdot \cdot{ }^{\prime} \cdot
$$

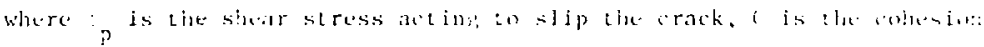

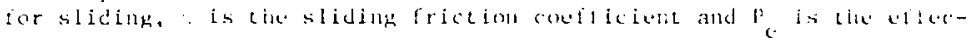
tive clamping stresti proviously detined.

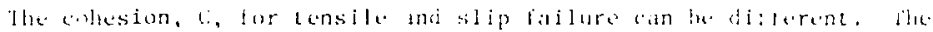

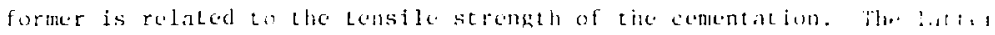

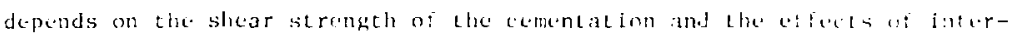
forence it the joint is rough or if the joint patern is irreatiat.

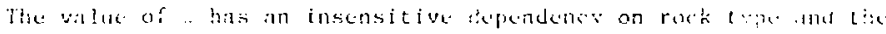

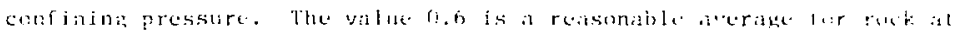

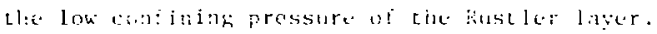

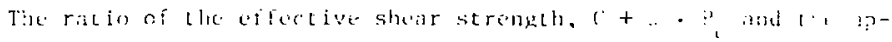

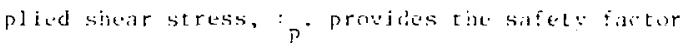

$$
F=\left(\left(+., \cdot P_{e}\right) / i_{i}:\right.
$$

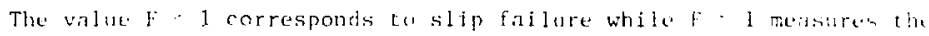

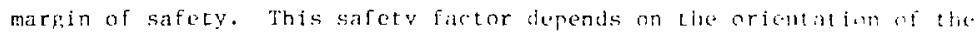
stress kensor to the crack plane and can be expressed ats

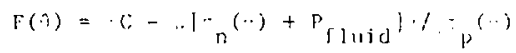

where $\therefore$ :epresents a particular orientation. The minimur vilue of l. I over a11 possible joint orientations provides the most conservative sality factor and is obtained in the followirs manner. 


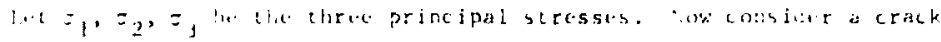

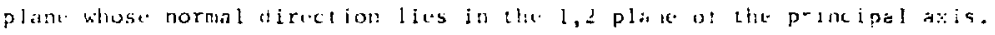

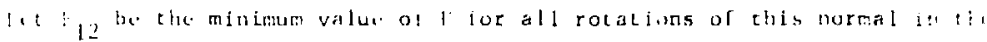
1,2 plane. Similar rumiark apply to the 2,3 and 3,1 planes. ihuth

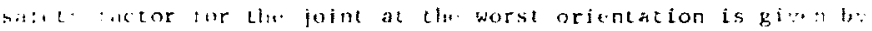

$$
E=\text { minimum } 2, \quad 11,1,3,13
$$

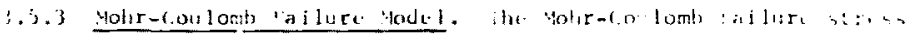
bustet ot lia concept ol internal triction is

$$
y=r_{0}+2-1 P-11110101
$$

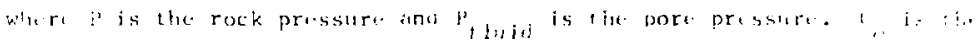

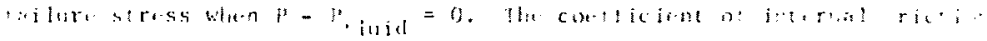

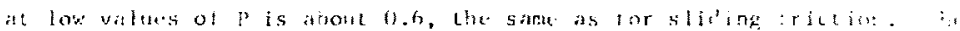

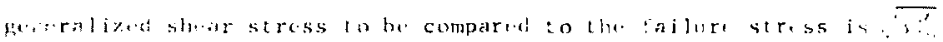
W.t.

$$
\overline{11^{\prime}}=\overline{\frac{1}{2}-121-23^{2}+12-21^{2}+12,-21^{2}}
$$

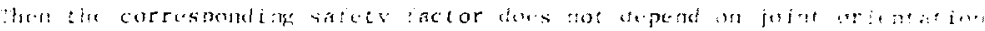
and is ition in:

$$
F \cdot=1 \% \overline{t_{3}^{\prime}}
$$

3. $\therefore$ Application of the Yolir-coulomb rodel. It was not pricticel 2 - sacian evero Rustler layer zone at all times. Instead, contour plots of $\overrightarrow{J_{2}^{\prime}}$ wereximined at $500,1000,1500$, and 2000 years lo find poteritial railure regions. A typical plot, corresponding lo 75HLE aL 1500 vars, is show in ligute 16. The uppermost contour is land is cencered in the bustler laver al a deps: of 200 meters and a range of 1100 meters. Init is the , the relatively large sciffness of this formation. This is land was well 


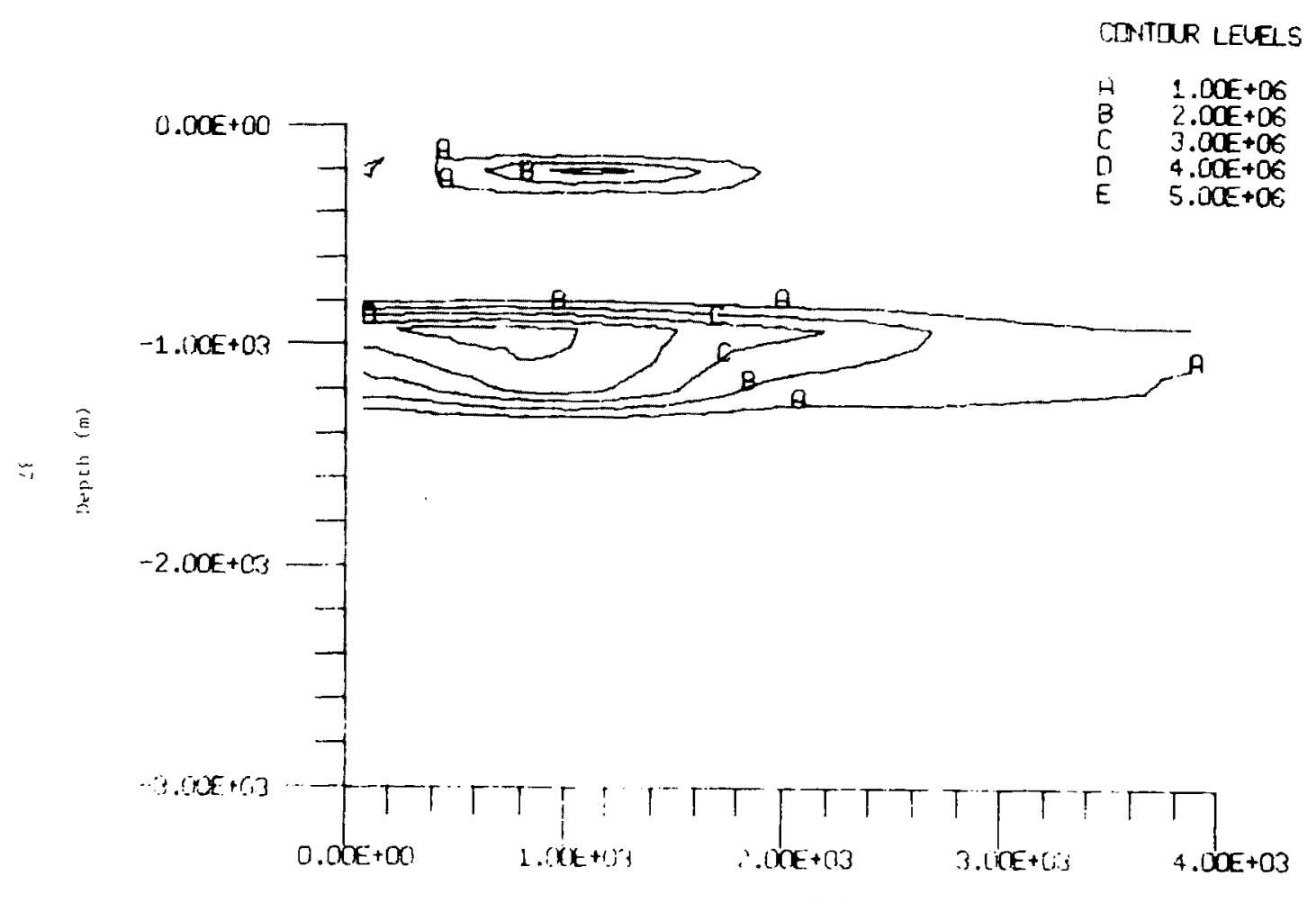


developed by 1000 years and was starting to decay by 2000 years. It did not migrate with the migrating surlace uplift peak.

the rime history of $\overline{\mathrm{J}^{\prime}}$ Cor the zone in tue middle of this is land is show in Figurs 17. Reading through the non-real ascil'ations, Lthe peals va], of $\sqrt{2}$ is $3.5,10^{6} \mathrm{~Pa}$ and occurs at about 750 years. It slowly decaxs, hecoming about $3.2 \times 10^{6}$ pa at 2000 years.

live corresponding aisplay of pressure is shown in Figure 18. The large initial rise and fall are not accurate because of the inherent oscillations. These are foirly well damped by 1000 years and a pressure or $9: 10^{6}$ l'a is a roblistic cotimate. The initial overburden pressurc is $5.5 \cdot 10^{6} \mathrm{~Pa}$, which is thice the joint sluid pressure by our assumption. l'sing $c_{0}=0$ the corrisponiting safoty factor testimate is

$$
r=1.2\left(9 \times 10^{6}-2.74 \div 10^{6}\right) /\left(3.2 \times 10^{6}: 3\right)=1.4
$$

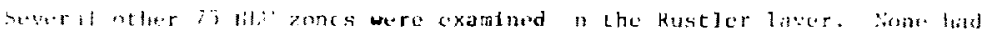
iurer satily ractors.

ih. Salec lactor for 30SF was sinilarly analyzed. In this case, the contours ai. $\bar{l}_{2}^{\prime}$ showed potential trouble in the kustler layer nearer the axis. nis Le history plots of $\sqrt{J_{2}^{\prime}}$ and $P$ were examined in this region.

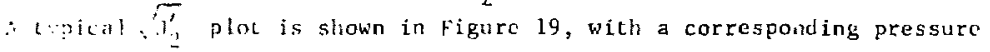
plot in ligure 20. Reaning through the unreal oscillations, the worst conditien ocers at about 500 years $\left(1.6 \times 10^{10} \mathrm{sec}\right)$ with $P=5.4 \therefore 10^{6}$ Pa :ne? $=3.010^{5} \mathrm{pa}$. The corresponding safety factor is then

$$
r=1.2\left(5.4 \cdot 10^{6}-2.74 \times 10^{6}\right) /\left(3.0 \times 10^{5} \cdot \sqrt{3}\right)=6.1
$$

intar rones fovi higher or similar results to the accuracy of estinating the averabe of the unreal oscillations. 


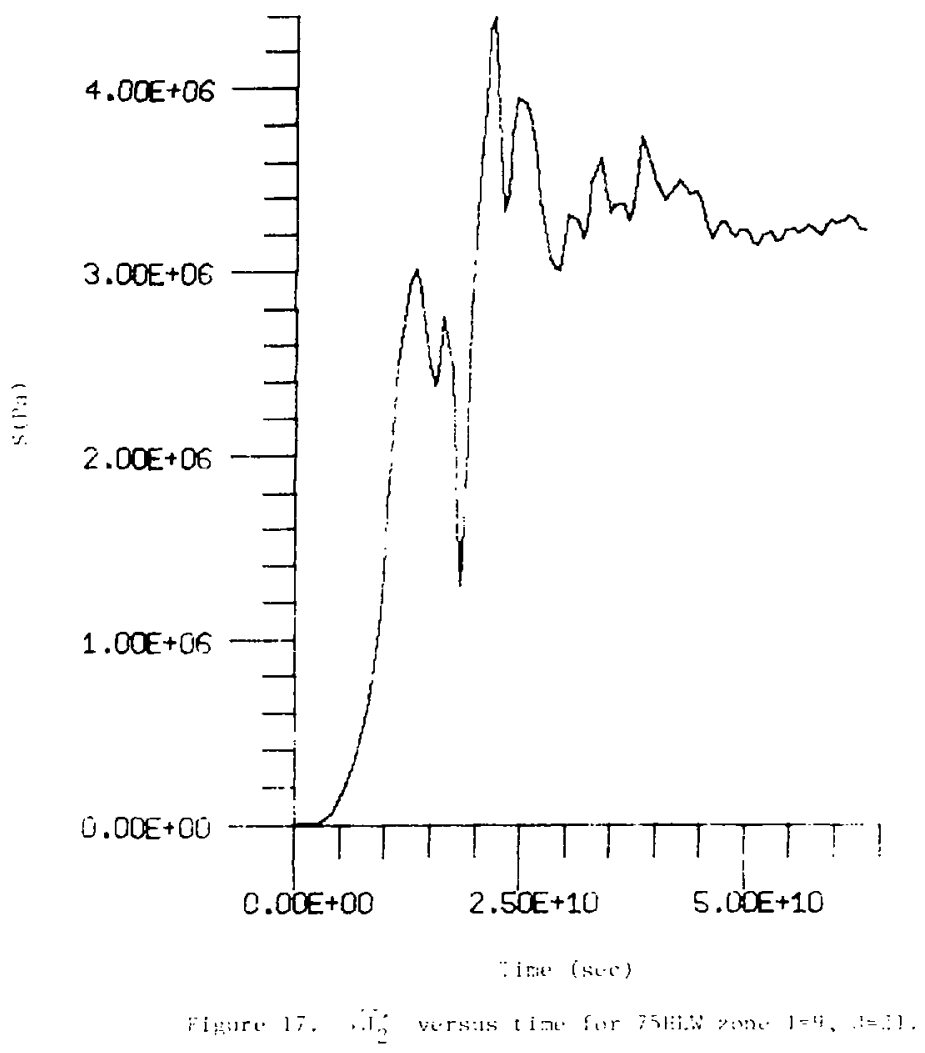




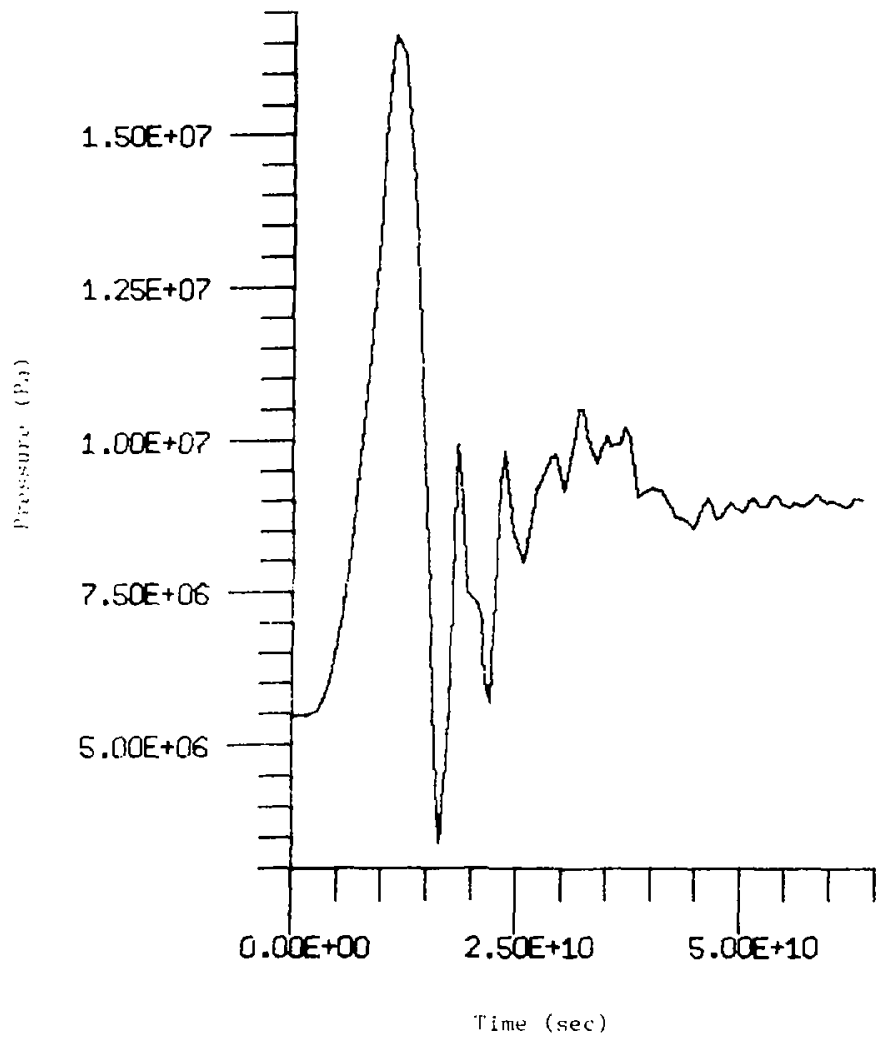

Figure 18. P versus time for $75 \mathrm{HLW}$ zone $[=9, \mathrm{~J}=21$. 


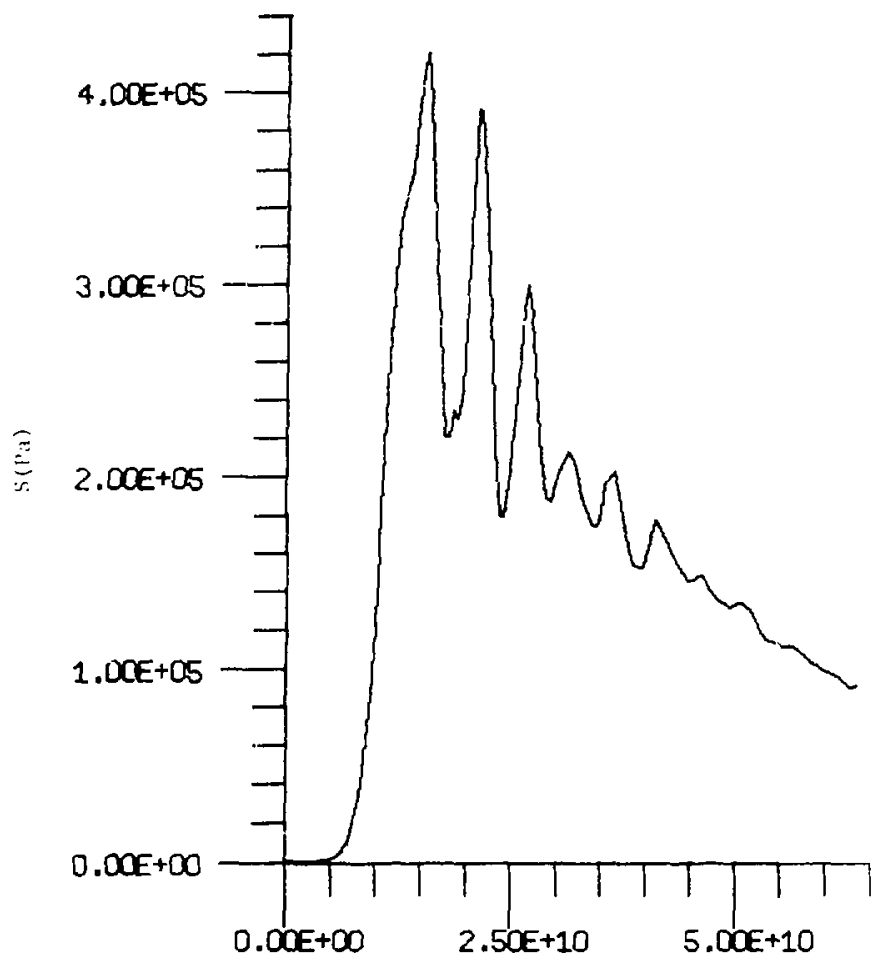

Tine (sec)

Figure 19. $\mathrm{JJ}_{2}$ versus time for $30 \mathrm{~s}$ zone $l=h, 1=21$. 


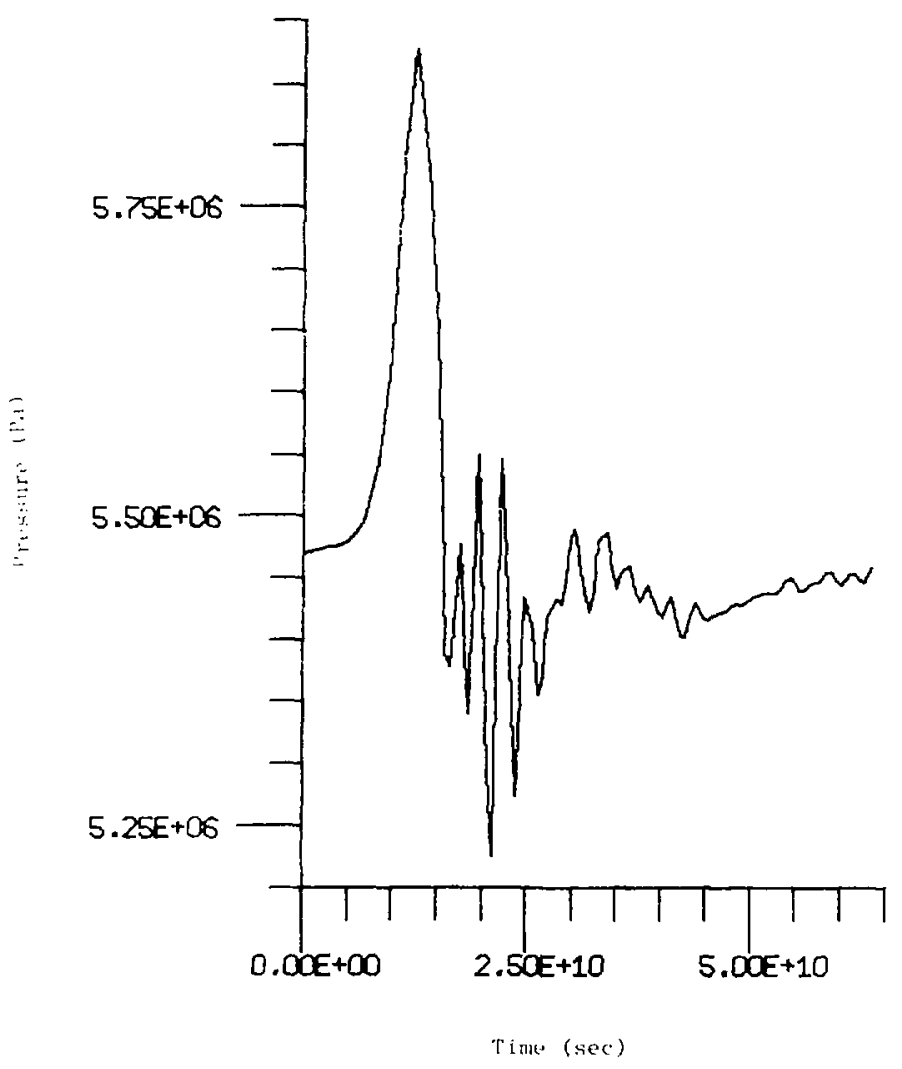

Fisure 26. P versus tinc for 3056 zone $1=6,1=21$. 


\section{5 .5 Application of the Joinc Siear Faidure lodel. A shori coje} was written to process che prirtout liata to obtain the anjle de ande: values of $F$ in the Rugriur laver at 1000 years under the ronserverivi ab-

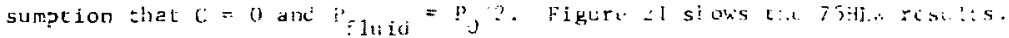

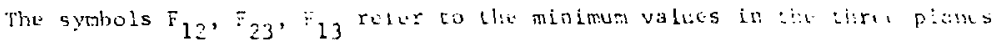
ot the principal axis. Tte I and 2 principal axis are boti is tac rasisis-

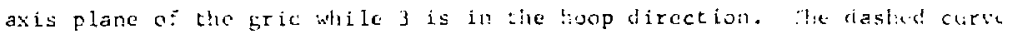
providus the tohr-coulomb $=F$. values for comparison.

The low and !; $\mathrm{gh}$ toversions near the axis are suspect for reasons pr.

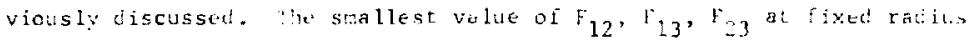
corresponds to F, the safety factor at the worst orientation. It is iste? ? but not always less than $:>$, the sohr-foulomb angle independen sait. inctor.

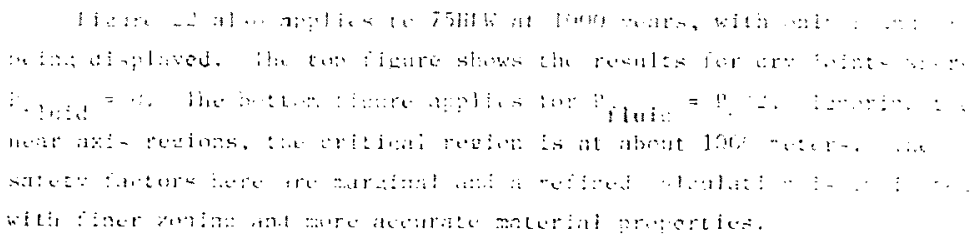

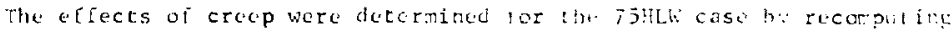
the first 2000 years with creep turned off, ltais thermovlastic calculation

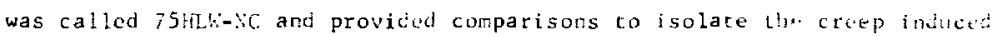
aifects. 


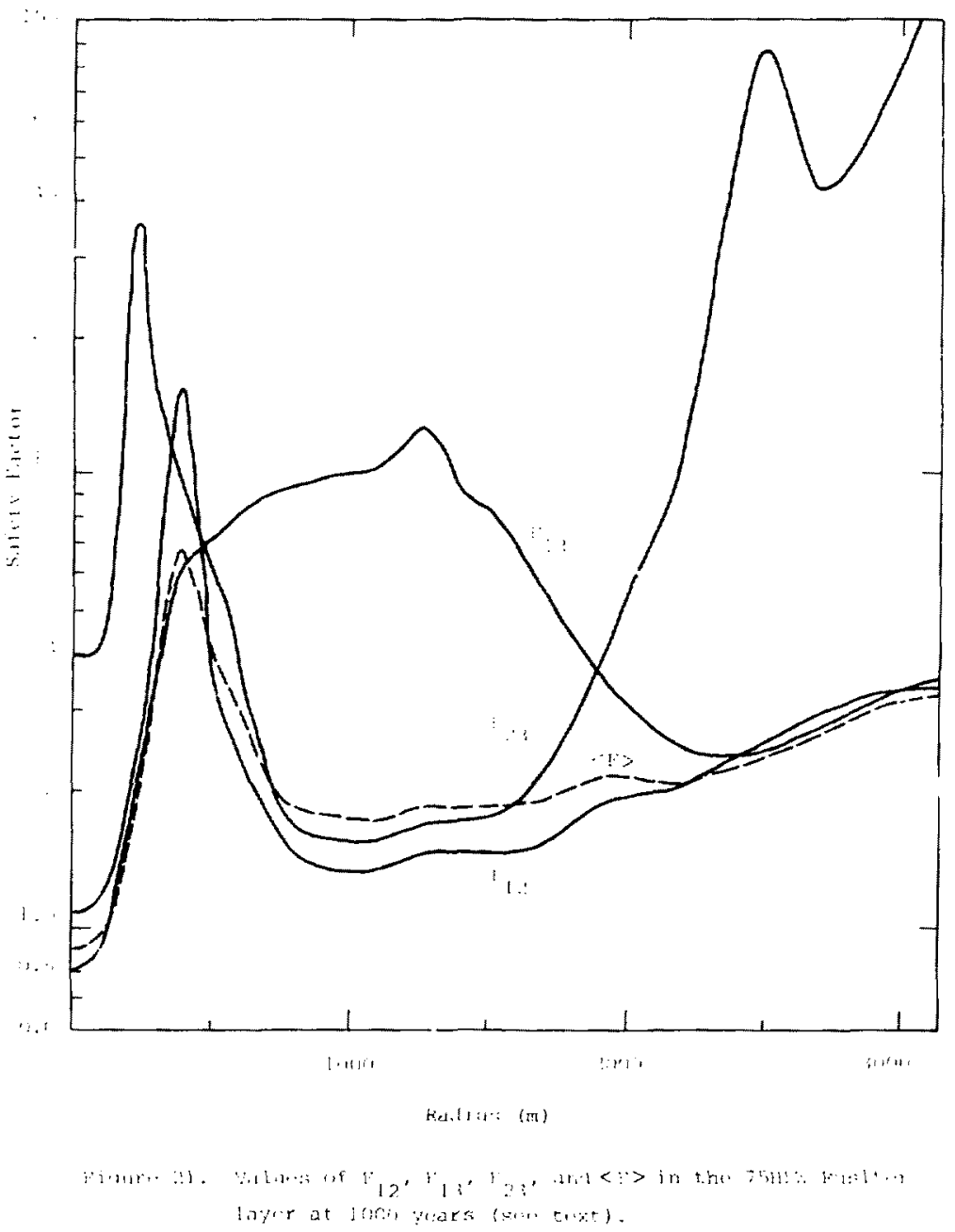

44 


$$
\text { W }
$$




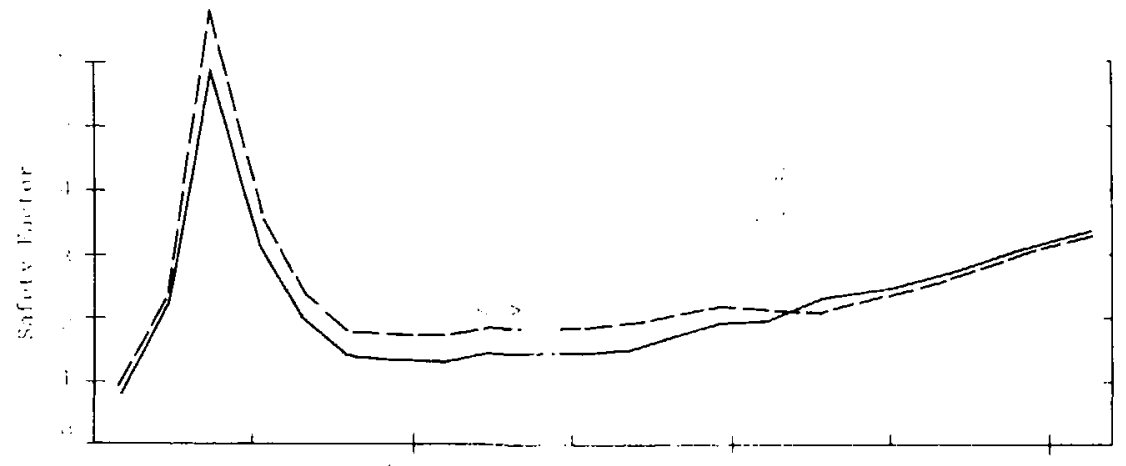

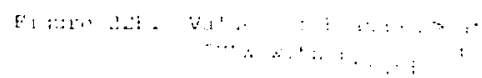




$$
\mathcal{V}
$$


$\stackrel{2}{\infty}$
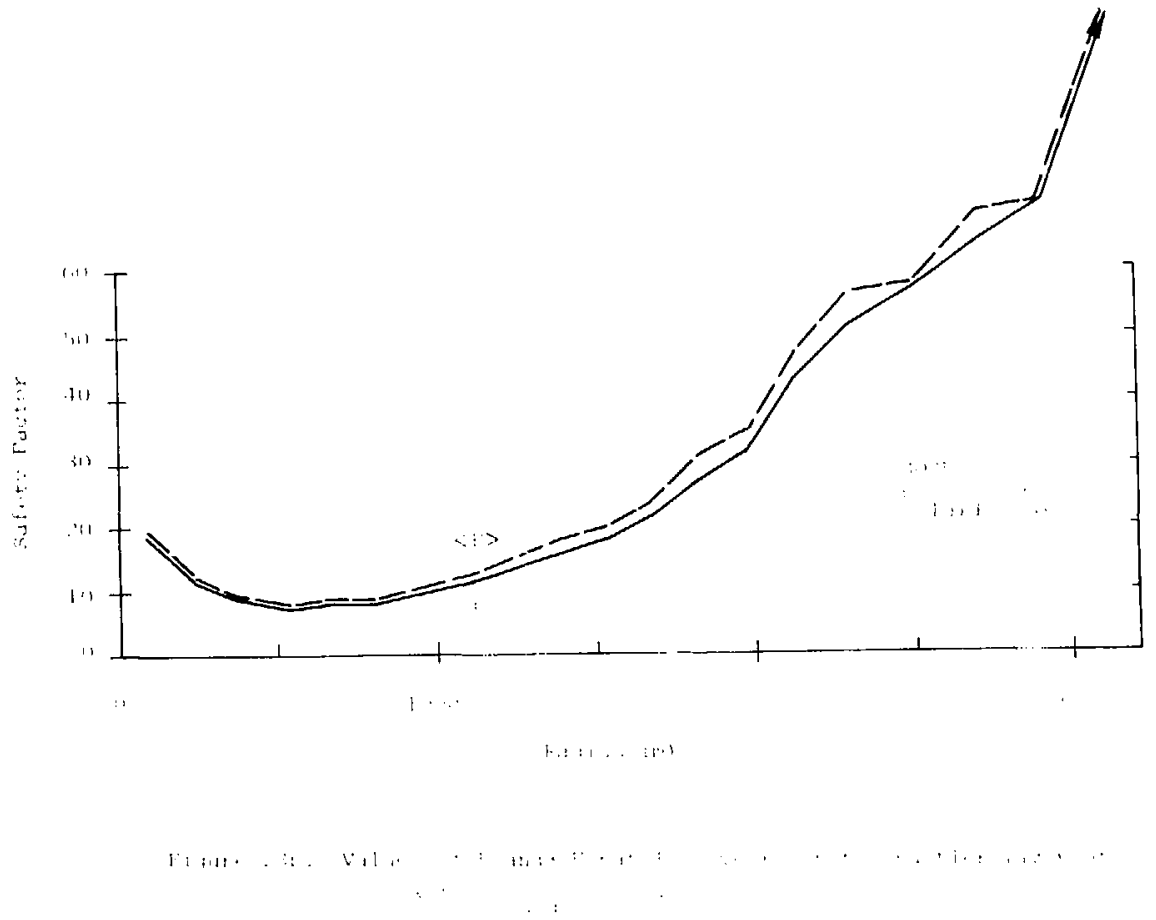


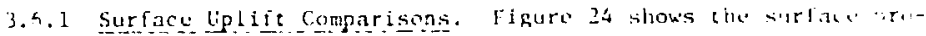

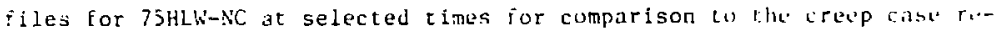
sults of Figuri lJ. "the creep case had larger peak uplifts dut to the

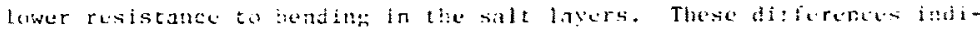

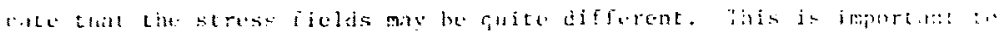
La, stabilicy oi the Rustler layer.

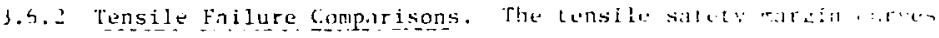

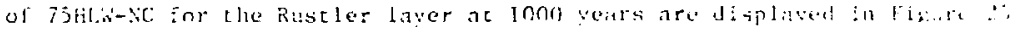

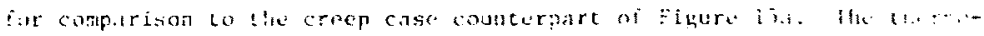

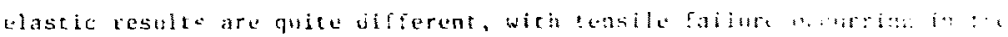

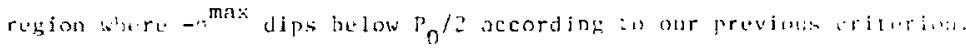

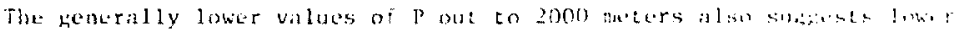
siluar fatilure siafety marajus.

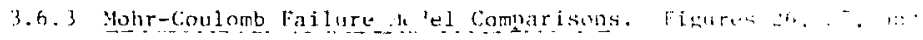

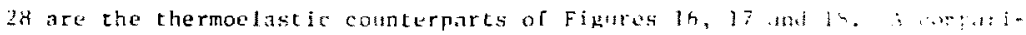
son of Figures 26 and 16 shows that the upper istand b: $\therefore$, whan: in:

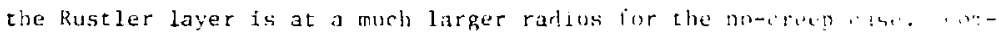

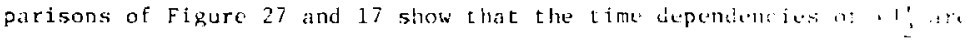

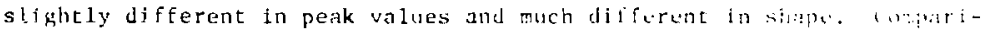

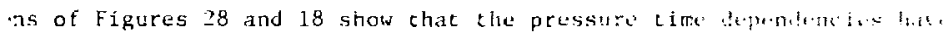

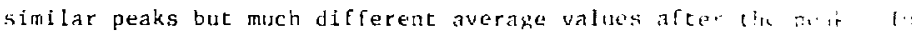

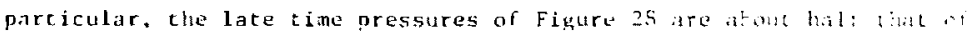
Figure 18. This has a large ef fect on the Yohr-foulomb sat $\because$ it:

Referring to the discussion of 3.5.4, the Figure 27 ard 2s latial 1000 vears (smoothing through the oscillations) indicale valuts ol $\because$,

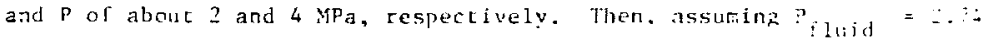
YPa as beforc, we nave

$$
\therefore F=1.2(4-2.75) /(2, \overline{3})=0.43
$$




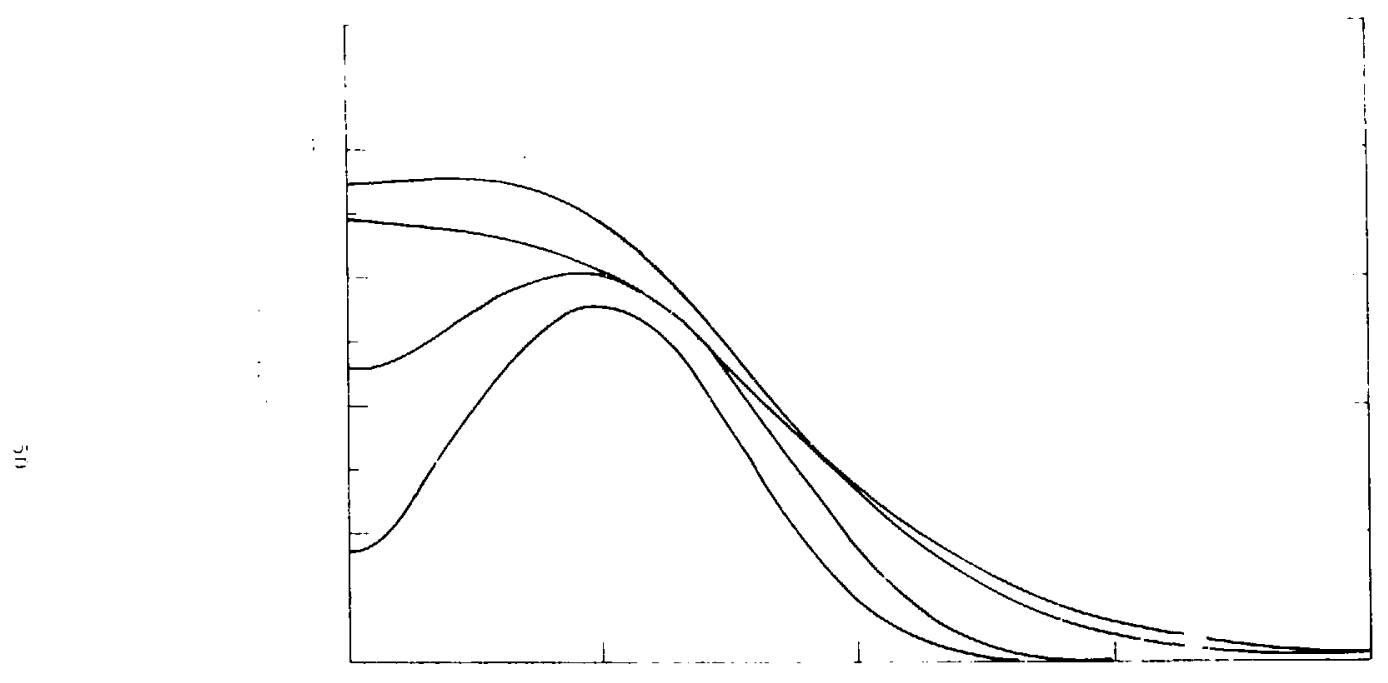


<smiles>C=CC=CCC</smiles> 


\section{CONTOR LEUES}
A $1.00 E+06$
B $2.00 \mathrm{TE}+06$
C 3.00E+06
D 4.00E+0S
E $5.00 E+06$

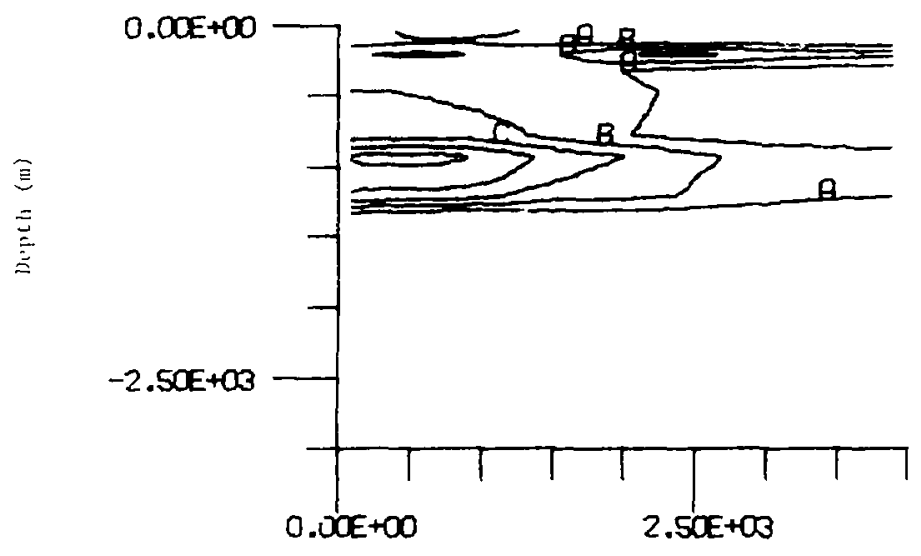

Kinge (m)

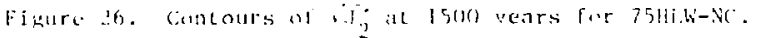




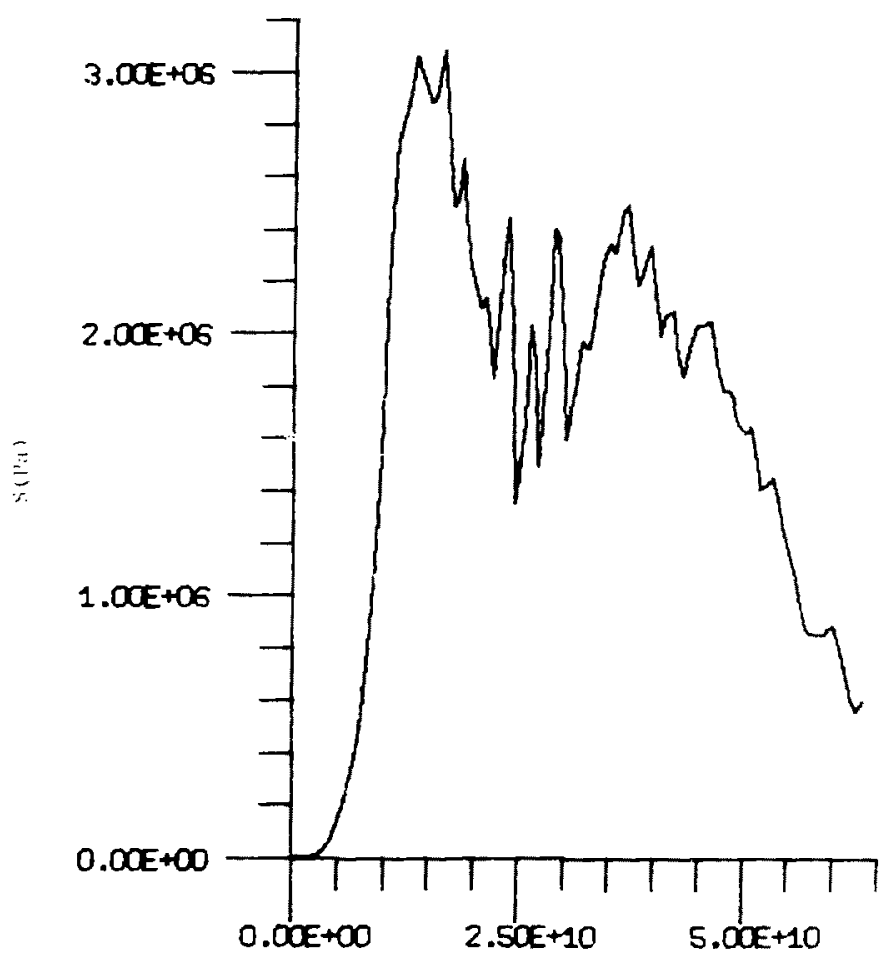

Tiste $(x+1)$

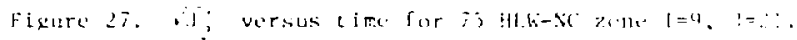




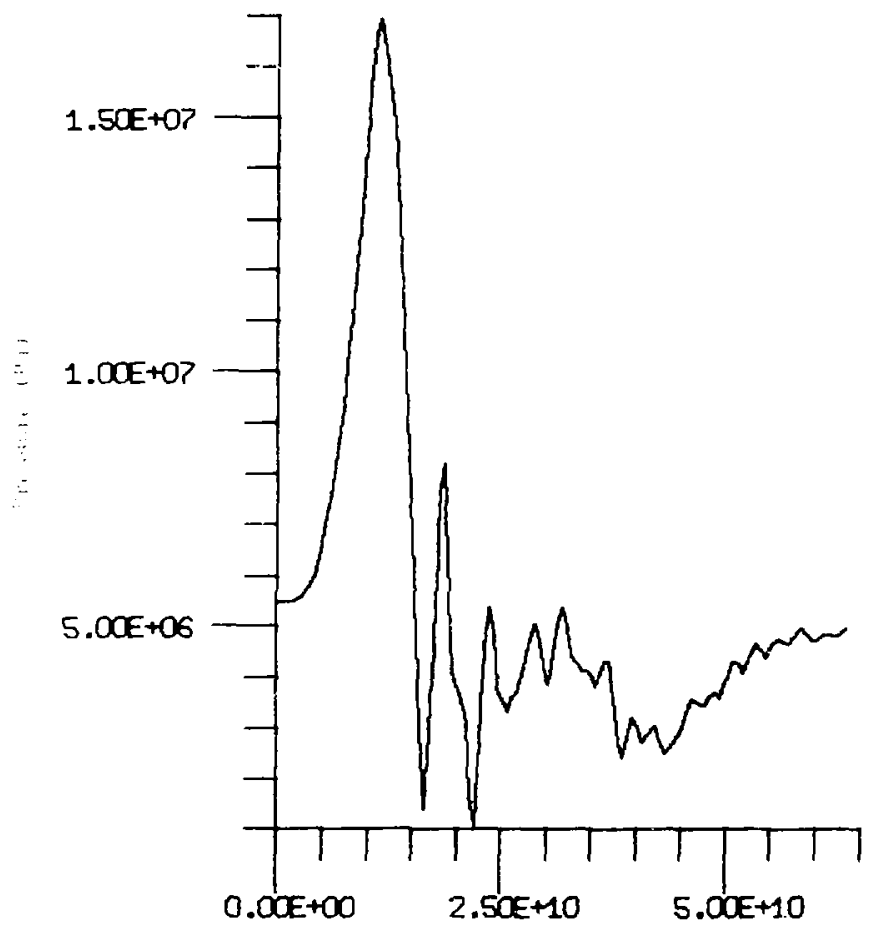

Timic (sec)

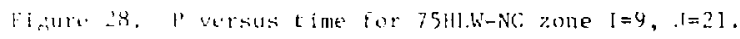


Thus the strength is only 437 of the generalized shear stress and the zone fails by this criterion. The corresponding creep case value was latre, which does net tait.

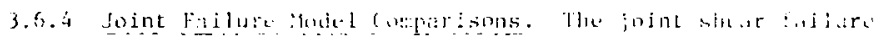

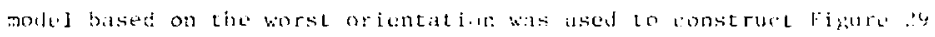

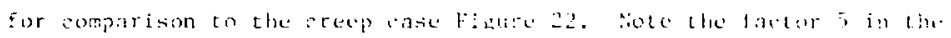

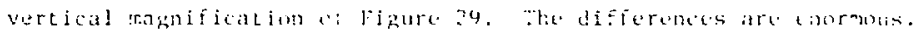

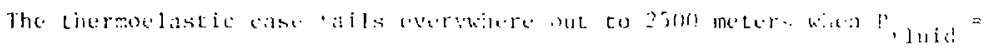

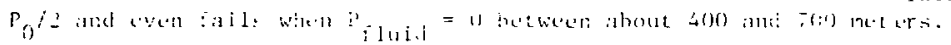




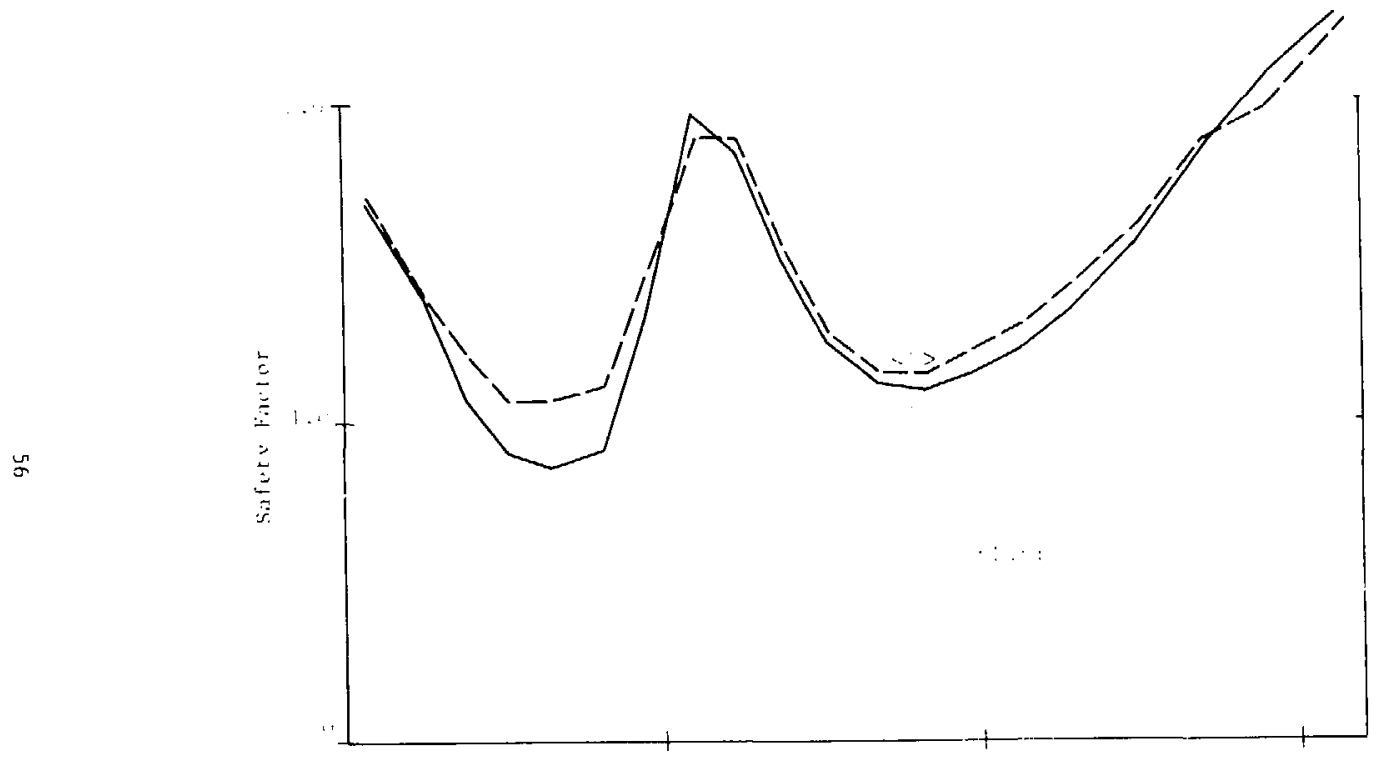




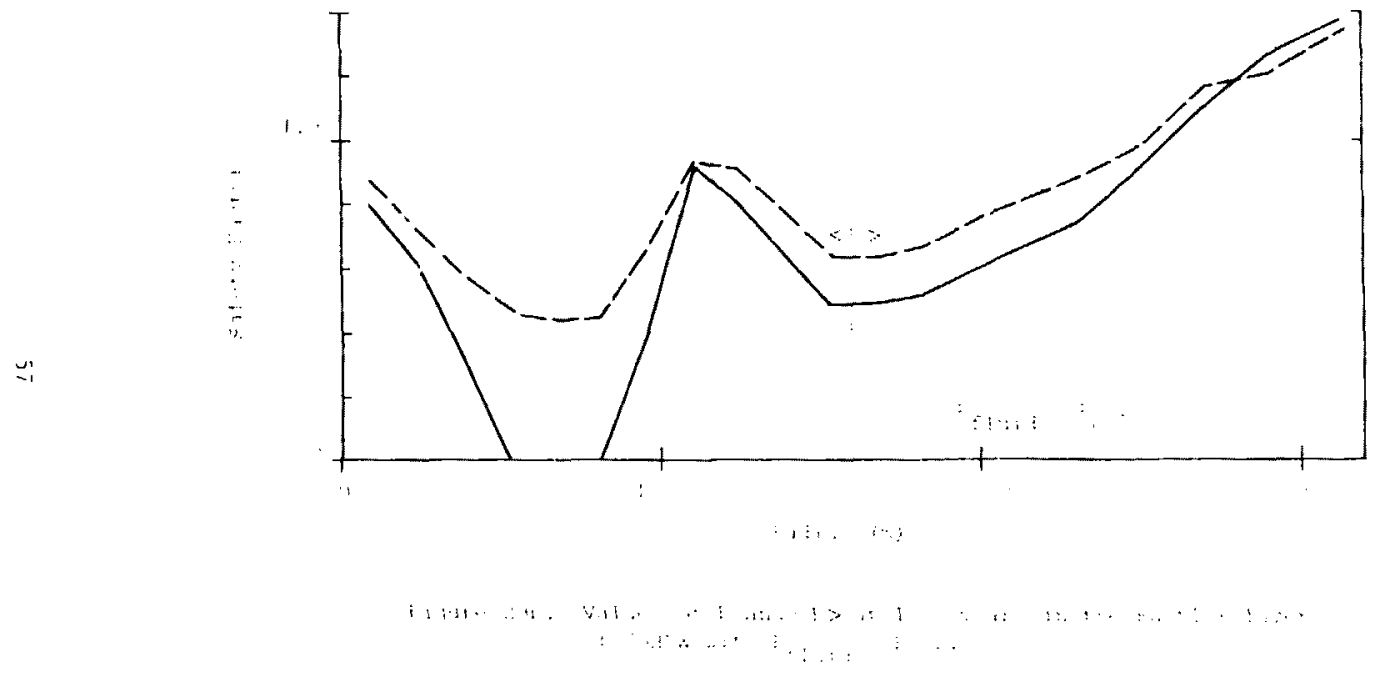


$\because 1.4119 ; 4$

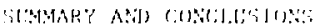

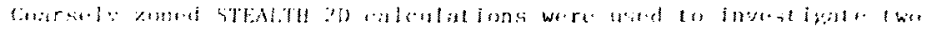

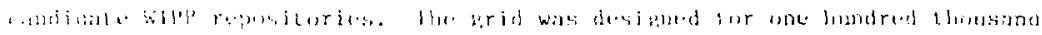

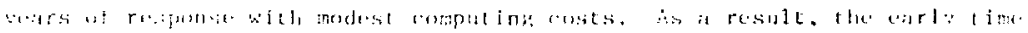

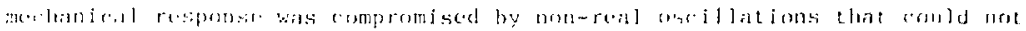

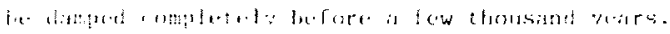

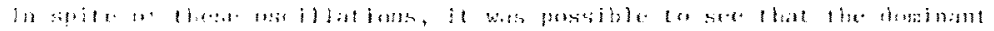

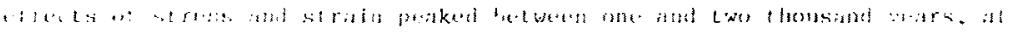

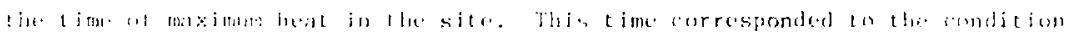

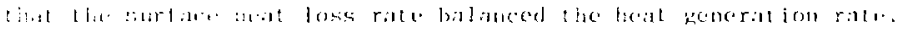

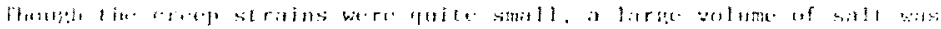

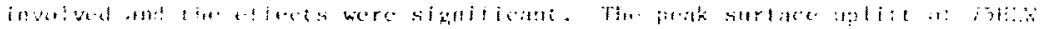

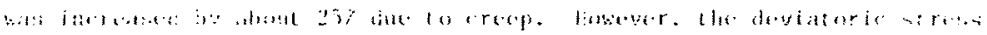

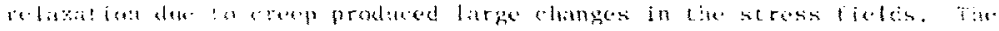

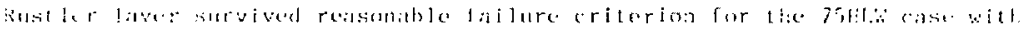

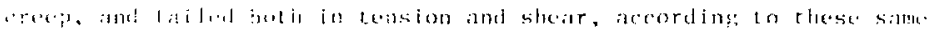

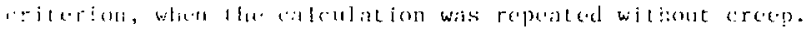

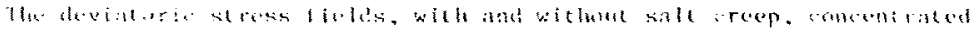

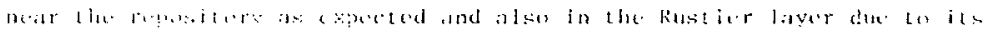

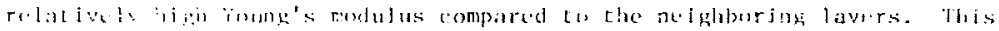

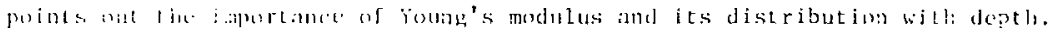

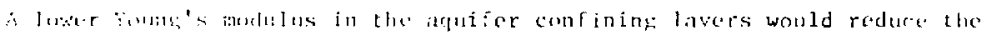

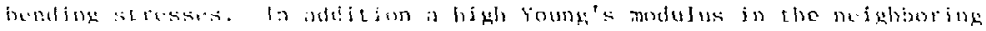

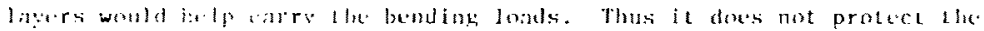

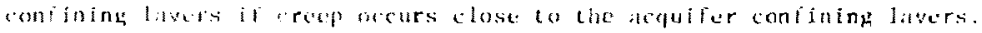

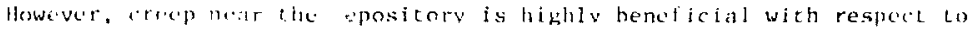

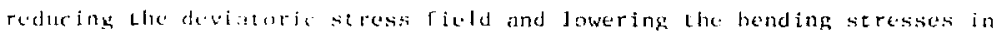
the upper strata. The tradeofi of these effects can be handled by conputer simulation cuen if chey niay not be traded off in a real repository. 


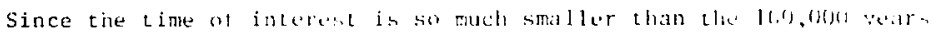

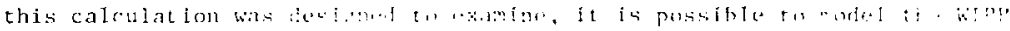

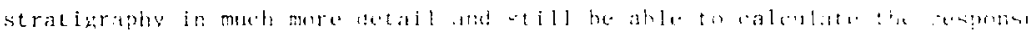

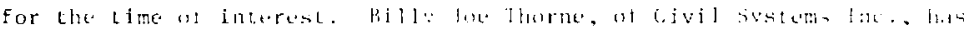

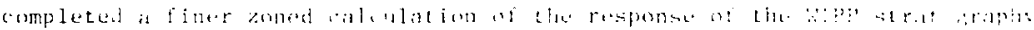

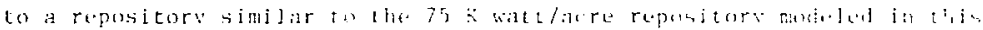

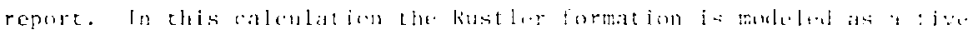

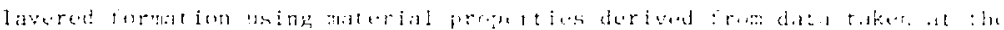

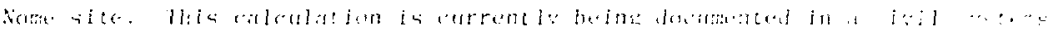

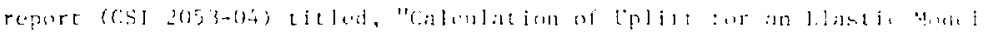

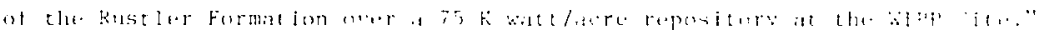




\title{
$\therefore$ L.T.IIII:;
}

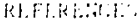

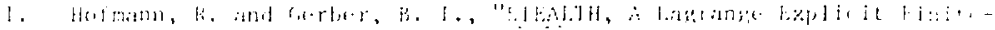
Hil:

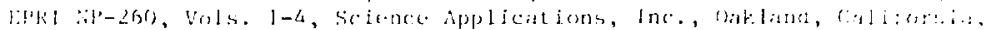

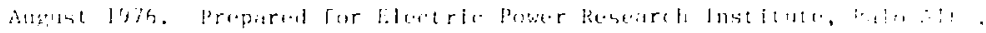
(al liturnit.

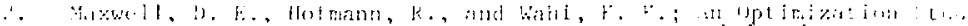

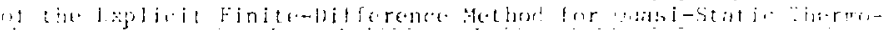

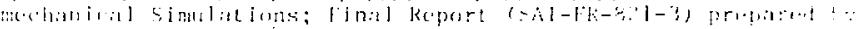

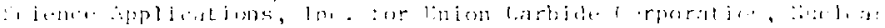

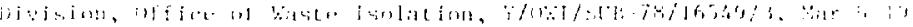

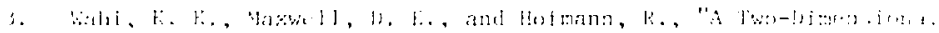

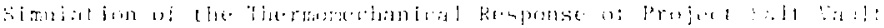

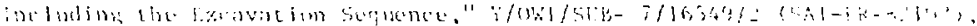

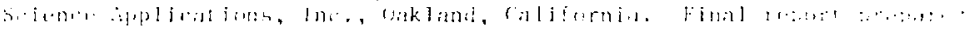

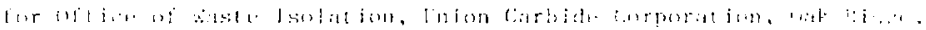

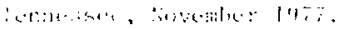

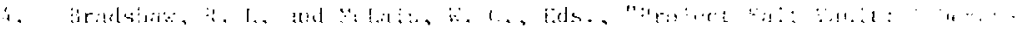

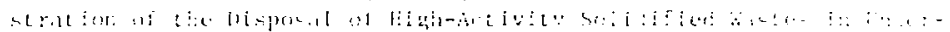

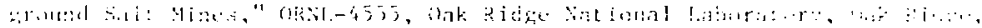
la

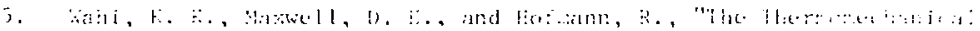

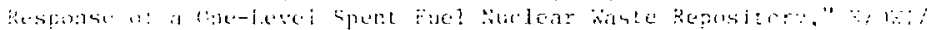
\$.

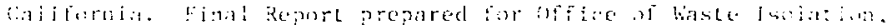

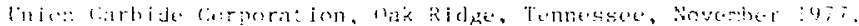

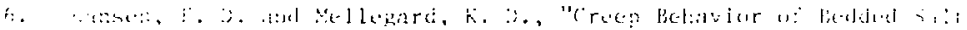

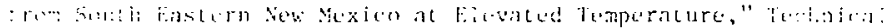

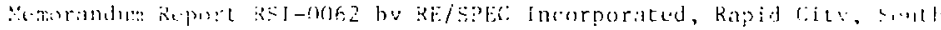

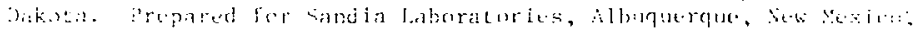
i.?

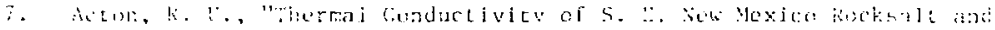

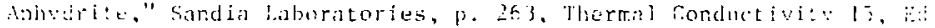
h: Glidimir Mirkovich. Plenum Press. 1978.

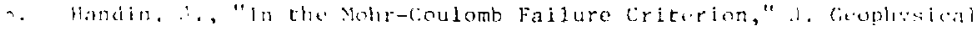

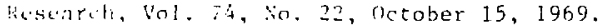

y. Buter, I. H., "Frictional Characteristics of Ciranite l'nder Hiph Confintng, lressute," i, of Ceophysical Researih. Vol. 72, No. lit. $141 \div 15,1967$. 